RECFIVED

ocT 131995

\title{
OSTI
}

\section{Data Fusion Qualitative Sensitivity Analysis}

\author{
E. A. Clayton \\ R. E. Lewis.
}

September 1995

Prepared for the U.S.Department of Energy under Contract DE-AC06-7.6RLO 1830

Pacific Northwest Laboratory

Operated for the U.S. Department of Energy by Battelle Memorial Institute 
This report was prepared as an account of work sponsored by an agency of the United States Government. Neither the United States Government nor any agéncy thereof, nor Battelle Memorial Institute, nor any of their employees, makes any warranty, express or implied, or assumes any legal liability or responsibility for the ccuracy, completeness, or usefulness of any information, apporatus, product, or procéss disclosed, or represents that its use would not infringe privately owned rights. Reference herein to any specific commercial product, process, or service by trade name, trademark, manufacturer, or otherwise does not necessarily constitute or imply its endorsement, recommendation, or favoring by the United States Government or any agency thereof, or Battelle Memorial institute. The views and opinions of authors expressed herein do not necessarily state or reflect those of the United States Government or any agency thereof.

\section{PACIFIC NORTHWEST LABORATORY operated by \\ BATTELLE MEMORIALINSTITUTE for the UNITED STATES DEPARTMENT OF ENERGY under Contract DE-ACO6-76RLO 1830}

\section{Printed in the United Strites of Amorica}

Available to DOE and DOE contractors from tho Office of Scientific and Technical Information, P.O. Box 62, Oak Ridge, TN 37831 ; priceś avạilable from (615) $576-840 \%$.

Avallable to the public from the National Tochunical information service,

$\because$ U.S. Department of Commeice, 5285, Port Royal Rd., springfield, VA 22161)

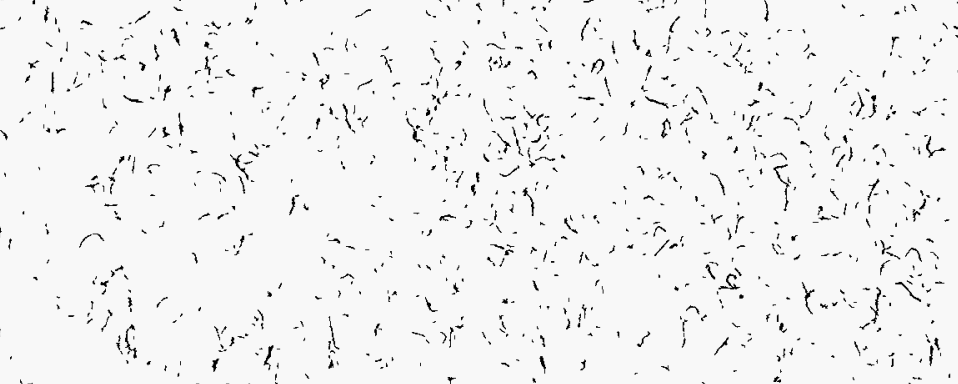


PNL-10393

UC-606

\title{
DATA FUSION QUALITATIVE SENSITIVITY ANALYSIS
}

\author{
E. A. Clayton \\ R. E. Lewis
}

September 1995

Prepared for the U.S. Department of Energy under Contract DE-AC06-76RLO 1830.

Pacific Northwest Laboratory

Richland, WA 99352

This work is funded by the Office of Technology Development, within the Department of Energy's Office of Environmental Management, under the Characterization, Monitoring, and Sensor Technology Integrated Program and the VOCs in Arid Soils Integrated Demonstration. 


\section{DISCLAIMER}

Portions of this document may be illegible in electronic image products. Images are produced from the best available original document. 


\section{SUMMARY}

Pacific Northwest Laboratory was tasked with testing, debugging, and refining the Hanford Site data fusion workstation (DFW), with the assistance of Coleman Research Corporation (CRC), before delivering the DFW to the environmental restoration client at the Hanford Site. Data fusion is the mathematical combination (or fusion) of disparate data sets into a single interpretation. The data fusion software used in this study was developed by CRC.

The data fusion software developed by CRC was initially demonstrated on a data set collected at the Hanford Site (Porter et al. 1994) where three types of data were combined. These data were 1) seismic reflection, 2) seismic refraction, and 3) depth to geologic horizons. The fused results included a contour map of the top of a low-permeability horizon.

This report discusses the results of a sensitivity analysis of data fusion software to variations in its input parameters. The data fusion software developed by CRC has a large number of input parameters that can be varied by the user and that influence the results of data fusion. Many of these parameters are defined as part of the earth model.

The earth model is a series of 3-dimensional polynomials with horizontal spatial coordinates as the independent variables and either subsurface layer depth or values of various properties within these layers (e.g., compression wave velocity, resistivity) as the dependent variables.

The earth model has a number of parameters that influence the data fusion:

- order of the polynomial

- initial mean values of the coefficients for each term

- standard deviation (sigma) for each coefficient

- overall sigma

- exponential correlation coefficient (tau)

- minimum and maximum allowable values of the polynomial.

Parameters for the earth model were varied and applied to different measurement data scenarios to determine their qualitative effects on the data fusion results. A synthetic data set, comprising stratigraphic contacts interpreted from well data (i.e., well picks), seismic reflection, and seismic refraction lines, was created for the analysis. The data types included in this study are the same as those used by CRC in their fusion demonstration (Porter et al. 1994); however, the synthetic data sets are simpler and represent a planar, two-layer earth section.

Several parameters in the earth model have a large influence on the data fusion results: 1) width sigma, 2) width tau, and 3) sigmas of polynomial coefficients. The overall sigma and tau control the allowable amplitude and "smoothness" of spatial variability in the fused results, respectively. If the user wants data fusion to honor the measurement data as best as possible, without exerting predefined controls on it, the initial earth model sigmas should be set relatively high and the taus relatively low. The magnitude of the coefficient sigmas has the greatest influence on how well groups of measurement data are honored by data.fusion.

This qualitative sensitivity analysis of data fusion affirmed the importance of a wellinformed user running the data fusion software. The user must realize that the values given to the numerous user-defined parameters can have a significant effect on the results. To avoid affecting the results unintentionally, the user should perform a sensitivity analysis for every problem by varying the input parameters slightly up and down and observing how much the results change. 


\section{ACKNOWLEDGMENTS}

This work was prepared with the support of the following contributors:

DOE Headquarters:

Office of Technology Development:

Caroline Purdy, Program Manager

Characterization, Monitoring, and Sensor Technology

Integrated Program

David Biancosino, Program Manager

Volatile Organic Compounds In Arid Soils Integrated

Demonstration (VOC-Arid ID)

DOE Richland Operations Office: Deborah E. Trader, Technical Program Officer

Richland Operations Office

Technology Development Division 


\section{CONTENTS}

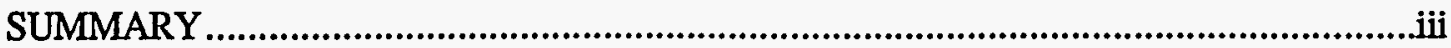

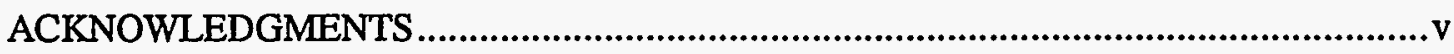

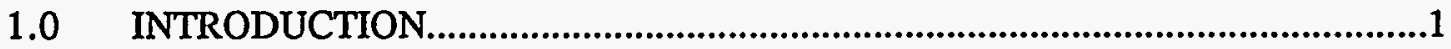

1.1 Purpose and Scope ....................................................................1

1.2 Background...............................................................................

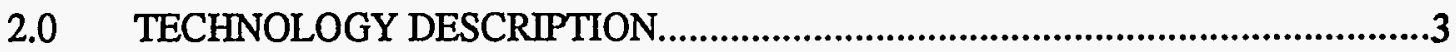

3.0 DATA SET, TEST DESCRIPTIONS, AND RESULTS .................................5

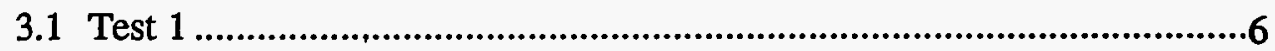

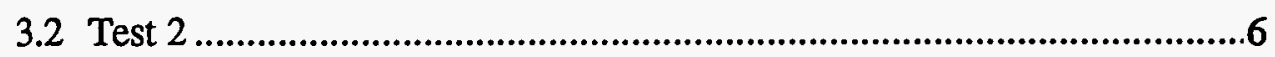

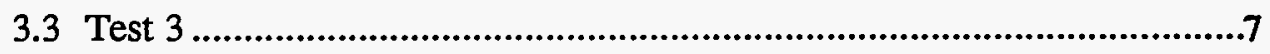

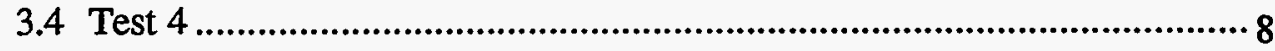

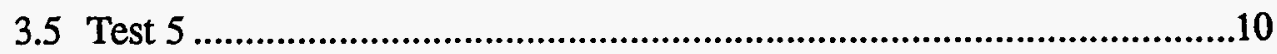

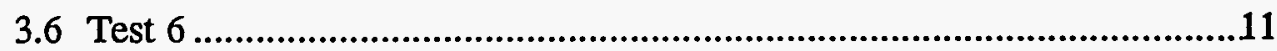

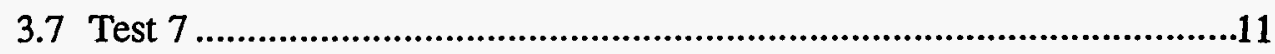

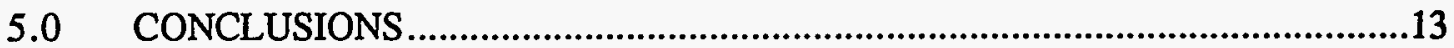

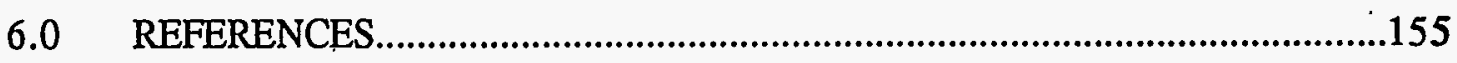




\section{TABLES}

$1 \quad$ Artificial Data Set Base Measurement Data..................................................5

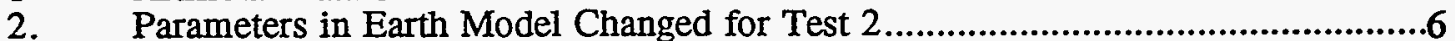

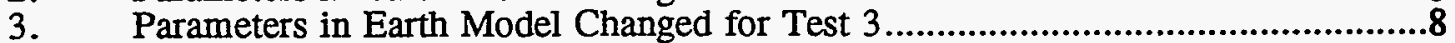

4. Parameters in Earth Model Changed for Test 4 ................................................9

5. Parameters in Earth Model Changed for Test 5................................................10

\section{FIGURES}

1 Synthetic Data Set and Earth Model Used for Data Fusion Sensitivity Analysis ..12

2. DFW Earth Model Width Polynomial Coefficient Specification Window...............15

3. DFW Earth Model Velocity Polynomial Coefficient Specification Window..........19

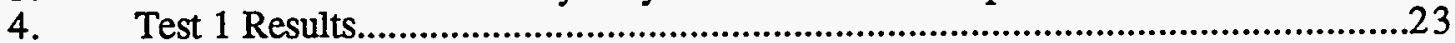

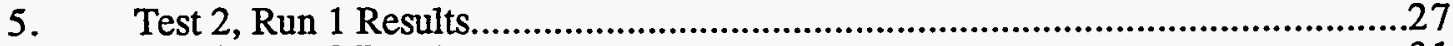

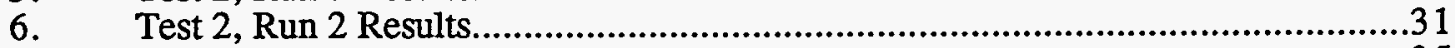

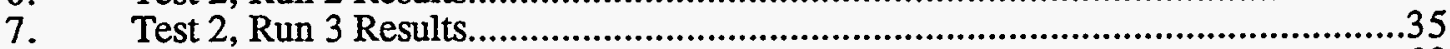

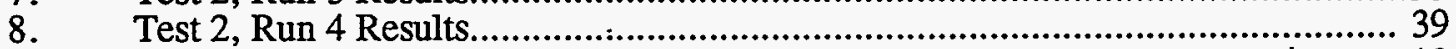

9. Test 2, Run 5 Results.................................................................................43

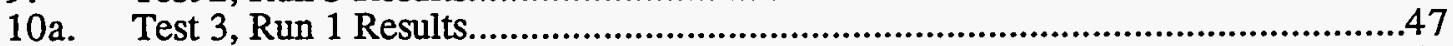

10b. Test 3, Run 1 Normalized Reflection Residuals Plot .........................................51

10c. Test 3, Run 1 Normalized Refraction Residuals Plot........................................55

10d. Test 3, Run 1 Normalized Well Pick Residuals Plot.............................................59

11. Test 3, Run 2 Results..................................................................................63

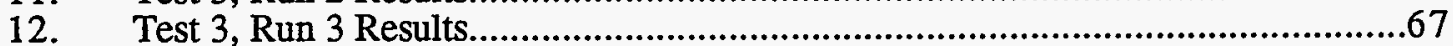

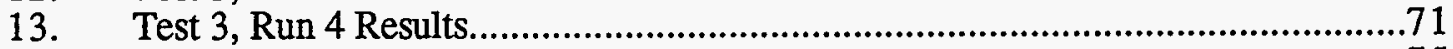

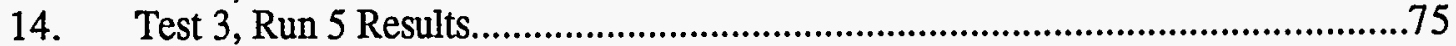

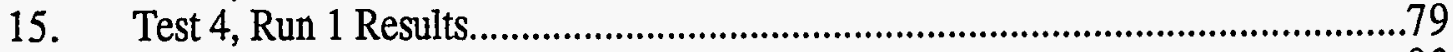

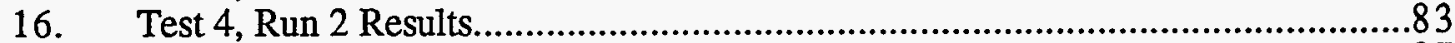

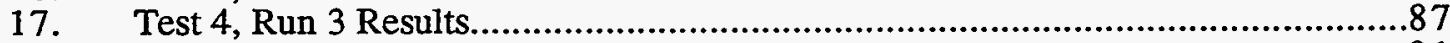

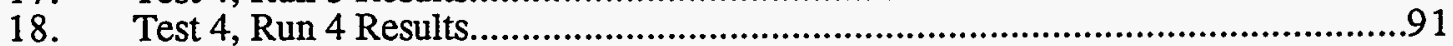

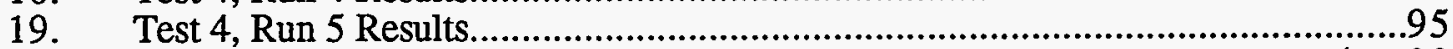

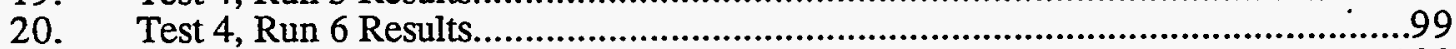

21. Test 4, Run 7 Results.............................................................................103

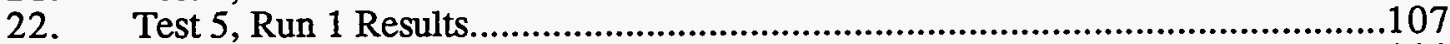

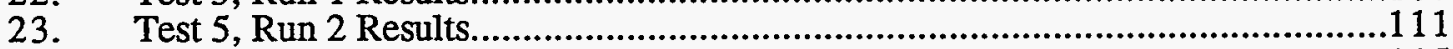

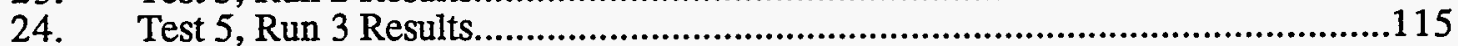

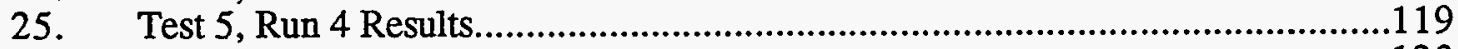

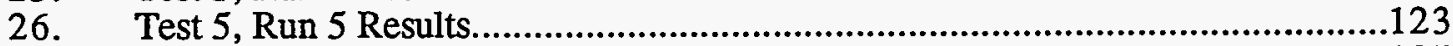

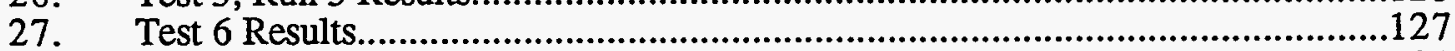

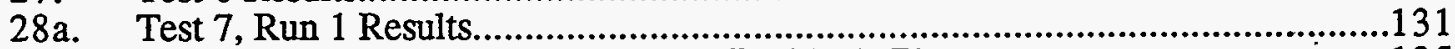

28b. Test 7, Run 1 Normalized Reflection Residuals Plot ........................................135

28c. Test 7, Run 1 Normalized Refraction Residuals Plot.........................................139

28d. Test 7, Run 1 Normalized Well Pick Residuals Plot.......................................143

29. Test 7, Run 2 Results..............................................................................147

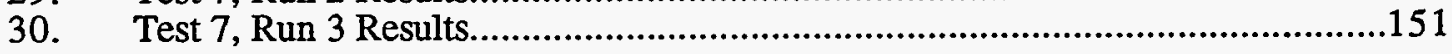




\subsection{INTRODUCTION}

\subsection{Purpose and Scope}

This study qualitatively analyzed the sensitivity of data fusion software to variations in its user-defined input parameters. The data fusion software, developed by Coleman Research Corporation (CRC) for use at the Hanford Site, has a large number of input parameters that can be varied by the user, especially in the earth model file. To produce the most accurate results, the user needs to be aware of how input parameters, and changes to them, affect the final, fused earth model. If the user chooses input parameters values that substantially affect the final results, or if the user is unaware of which input parameters produce the most representative solutions, the confidence in the data fusion software solutions will be reduced.

Various parameters for the earth model were applied to different measurement data scenarios to determine their qualitative effects on the data fusion results. A synthetic data set comprising well picks, seismic reflection, and seismic refraction lines was created for the analysis. The measurement data represented a simple two-layer earth section. By using this simple, multi-sensor synthetic data set, the data fusion results were compared to a known solution to determine how well the software honored the data.

\subsection{Background}

Data fusion is a discipline that seeks to combine data from multiple sensors to perform inferences that may not be possible from a single sensor alone. It is a fairly mature technology that has been developed for military applications plus other diverse areas such as robotics, traffic control, and office management (Hall 1992).

The implementation of data fusion used in this study was developed by CRC for the U.S. Department of Defense. CRC adaptation its data fusion technology for use in the environmental mission of the Department of Energy. CRC's initial adaptation efforts have been focused at the Hanford and Savannah River sites (Porter et al. 1994).

CRC developed a platform for their data fusion software, the data fusion workstation (DFW). The DFW is a Silicon Graphics Onyx, UNIX-based workstation. Programs on the DFW are the data fusion software, Dynamic Graphics Earth Vision ${ }^{T M}$ visualization software, INGRES relational database, a user interface developed with INGRES 4GL, CFEST groundwater modeling software, and GSLIB geostatistical software.

Pacific Northwest Laboratory (a) (PNL) received the DFW in June 1993, and was tasked with testing, debugging, and refining the DFW, with the assistance of CRC, before the workstation was delivered to the environmental restoration client at the Hanford Site in September 1994.

a PNL is operated for the U.S. Department of Energy by Battelle Memorial Institute, under contract DEAC06-76RLO 1830. 


\subsection{TECHNOLOGY DESCRIPTION}

CRC's implementation of data fusion uses a nonlinear, least-squares model to mathematically fuse various sensor data into a single interpretation. The mathematics were initially developed to calculate the position of orbiting bodies (Bierman 1977). The technology has been refined significantly, and the system developed for the Hanford Site fuses surface geophysical data (seismic refraction, seismic reflection, DC resistivity, frequency domain electromagnetics, and/or time domain electromagnetics) with stratigraphic contacts interpreted by a geologist from well data.

The CRC system applies commercially available forward models to a pre-defined earth model of a site. The earth model is a series of 3-dimensional polynomials (e.g., $z$ is a function of $x$ and $y$ ), with horizontal spatial coordinates as the independent variables ( $x$ and $y)$, and either subsurface layer depth or values of various properties within these layers (e.g., compression wave velocity, resistivity) as the dependent variables (z). A forward model determines the measurements that would result if a sensor (e.g., a geophysical tool) were applied to the earth model. For example, a reflection seismic forward model would produce, ideally, the measurements, which in this case is a seismic line, that would result from acquiring reflection data over an earth identical to the earth model.

The results of the forward models are compared to actual site data and residuals are computed. An iterative, least-squares regression process ensues where the earth model is adjusted step-wise until the forward models and measurement data agree within set statistical parameters. Sophisticated optimization algorithms are used to adjust the earth model during this iterative process. The final, adjusted earth model is the fused interpretation of the subsurface data.

For each earth model polynomial, a number of parameters define and influence the data fusion treatment:

- order of the polynomial

- initial mean values of the coefficients for each term

- standard deviation (sigma) for each coefficient

- width sigma

- exponential correlation coefficient (tau)

- minimum and maximum allowable values of the polynomial.

The polynomial order (e.g., first, second, etc.) and term coefficients are self-explanatory. Because each term coefficient is a random variable, each has a sigma. The overall or width sigma is the standard deviation of the random variation about the polynomial mean, and the exponential correlation (tau) is defined as the distance at which the correlation between spatial points decays to 1/e (0.37) (Gibbs 1993). The minimum and maximum allowable values are simply overall limits on the polynomial parameters, and are used to constrain the iterative, regression process.

Because the data fusion software addresses 3-dimensional problems, it loads the data and processes it within an internal grid system. The user defines the grid size and spacing for the problem in the initial earth model. In addition, each data measurement entering data fusion has a user-assigned sigma that reflects the user confidence in each measurement. 
…..... 


\subsection{DATA SET, TEST DESCRIPTIONS, AND RESULTS}

An artificial data set was created to perform the input parameter sensitivity tests on the DFW. This data set is shown in Figure 1 and consists of two layers separated by a planar boundary at 100 meters below the ground (mbgs). The top and bottom layers had seismic compressional-wave velocities of 1,000 meters/second $(\mathrm{m} / \mathrm{s})$ and $10,000 \mathrm{~m} / \mathrm{s}$, respectively.

Subsurface data are provided by geologic picks (e.g., depth to the layer boundary) for 15 wells and several seismic lines. The wells are arranged in a three by five matrix, and each well is separated from its neighbor by 50 meters. Two 260-meter-long seismic reflection lines with 27 mid-point gathers each (10-meter spacing between gathers) bisect the three columns of wells. Two lines of seismic refraction data, with 6 shot points each and 10-meter receiver spacing, coincide with the reflection lines.

Seismic data measures the position of a layer boundary in units of time and well picks are in units of distance. Thus, the acoustic travel times to the layer boundary, as measured in the reflection data, must be converted to depths through application of the upper layer's compressional velocity. The refraction data provides the required necessary seismic velocities. Otherwise, the only source of velocity information would be the earth model.

An initial earth model was constructed within the INGRES 4GL from the artificial data set for input into the DFW. (Figures 2 and 3 are examples of the 4GL). The initial earth model matches the artificial data set exactly (same layer depths and compressional velocities) and is used as a baseline for the sensitivity analyses. The numerical parameters input into the initial earth model are listed in Table 1.

Table 1. Artificial Data Set Base Measurement Data

\begin{tabular}{|l|l||}
\hline number of layers & 2 \\
\hline layer boundary & 100 mbgs \\
\hline well pick sigma & 2 meters \\
\hline seismic reflection measurement two-way travel time sigma & 3 milliseconds \\
\hline seismic refraction measurement two-way travel time sigma & 4 milliseconds \\
\hline width polynomial order & 2 \\
\hline width polynomial exponential correlation coefficient & 150 meters \\
\hline width sigma & 3 meters \\
\hline width polynomial constant coefficient & 100 meters \\
\hline width polynomial constant coefficient sigma & 10 meters \\
\hline other width polynomial coefficients & 0 meters \\
\hline overall compression velocity sigma (both layers) & 50 meters/second \\
\hline top layer seismic compressional-wave velocity & 1,000 meters/second \\
\hline bottom layer seismic compressional-wave velocity & 10,000 meters/second \\
\hline compressional velocity data polynomial order (both layers) & 2 \\
\hline compressional velocity exponential correlation coefficient & 150 meters $\cdot$ \\
\hline compressional velocity sigma (both layers) & 50 meters/second \\
\hline compressional velocity constant coefficient (upper layer) & 1,000 meters/second \\
\hline compressional velocity constant coefficient sigma (upper layer) & 50 meters/second \\
\hline compressional velocity constant coefficient (lower layer) & 10,000 meters/second \\
\hline compressional velocity constant coefficient sigma (lower layer) & 50 meters/second \\
\hline other compressional velocity coefficients (both layers) & 0 meters/second \\
\hline grid spacing & 50 meters \\
\hline \hline
\end{tabular}


The base measurement data set and earth model were adjusted for each specific test and their representative files were read as input to the data fusion software. Once the data fusion run was completed successfully, EarthVision ${ }^{\mathrm{TM}}$ visualization software grid files were created from the output fusion grid file through an INGRES 4GL interface. The results of each test were viewed in EarthVision ${ }^{\mathrm{TM}}$ and plotted. The purpose for each analysis, the parameters changed, and their affect upon the fused results are discussed below.

\subsection{Test 1}

Test 1 consisted of running the data fusion software with a perfectly matched base data set and initial earth model. The purpose of this test was to ensure the stability of the data fusion software by using a basic problem where the initial earth model and measurement data exactly matched each other. If the data fusion process would have had diverged from the initial earth model, the software results would have been inaccurate.

The fused earth model closely matched the original earth model from which the synthetic measurement data were generated. The top and bottom layer velocities were very close to $1,000 \mathrm{~m} / \mathrm{s}$ and $10,000 \mathrm{~m} / \mathrm{s}$, respectively, and the boundary between the layers was very flat and centered around 100 mbgs (Figure 4). (Note: the velocities can be determined by using the color key in the lower left corner of the figure.) The one sigma confidence bounds on the layer boundary were very small as well. The data fusion program was very stable in this simple test.

\subsection{Test 2}

The purpose of Test 2 was to determine how well the fused results would converge on the actual data set, when the initial earth model was not representative of the actual data set. Test 2 used the same data set as the Test 1, but the earth model was adjusted so that it differed from the data set with respect to the upper layer thickness and the seismic velocities of the two layers; the constant coefficient for the width polynomial and the constant coefficients for both velocity polynomials (upper and lower layers) were changed. These width and velocity aberrations were used in five separate data fusion runs to isolate their effects on the final results. Table 2 lists the changes made to the earth model.

Table 2. Parameters in Earth Model Changed for Test 2

\begin{tabular}{||l|c|c|c|c|c|c||}
\hline \begin{tabular}{|} 
Parameters Changed in Earth \\
Model
\end{tabular} & $\begin{array}{c}\text { Initial Earth } \\
\text { Model }\end{array}$ & Run 1 & Run 2 & Run 3 & Run 4 & Run 5 \\
\hline $\begin{array}{l}\text { width polynomial constant } \\
\text { coefficient }\end{array}$ & $100 \mathrm{~m}$ & $50 \mathrm{~m}$ & Initial & Initial & Initial & Initial \\
\hline $\begin{array}{l}\text { width polynomial non-constant } \\
\text { coefficients }\end{array}$ & $0 \mathrm{~m}$ & Initial & $50 \mathrm{~m}$ & Initial & Initial & Initial \\
\hline $\begin{array}{l}\text { overall compressional velocity } \\
\text { sigma (upper layers) }\end{array}$ & $50 \mathrm{~m} / \mathrm{s}$ & Initial & Initial & Initial & $250 \mathrm{~m} / \mathrm{s}$ & Initial \\
$\begin{array}{l}\text { overall compressional velocity } \\
\text { sigma (lower layers) }\end{array}$ & $50 \mathrm{~m} / \mathrm{s}$ & Initial & Initial & Initial & $2,500 \mathrm{~m} / \mathrm{s}$ & Initial \\
$\begin{array}{l}\text { compressional velocity constant } \\
\text { coefficient (upper layer) }\end{array}$ & $1,000 \mathrm{~m} / \mathrm{s}$ & Initial & Initial & $500 \mathrm{~m} / \mathrm{s}$ & $500 \mathrm{~m} / \mathrm{s}$ & $500 \mathrm{~m} / \mathrm{s}$ \\
\hline $\begin{array}{l}\text { compressional velocity constant } \\
\text { coefficient (lower layer) }\end{array}$ & $10,000 \mathrm{~m} / \mathrm{s}$ & Initial & Initial & $15,000 \mathrm{~m} / \mathrm{s}$ & $15,000 \mathrm{~m} / \mathrm{s}$ & $15,000 \mathrm{~m} / \mathrm{s}$ \\
\hline $\begin{array}{l}\text { lompressional velocity constant } \\
\text { coefficient sigma (upper layer) }\end{array}$ & $50 \mathrm{~m} / \mathrm{s}$ & Initial & Initial & Initial & Initial & $300 \mathrm{~m} / \mathrm{s}$ \\
\hline $\begin{array}{l}\text { compressional velocity constant } \\
\text { coefficient sigma (lower layer) }\end{array}$ & $50 \mathrm{~m} / \mathrm{s}$ & Initial & Initial & Initial & Initial & $2,500 \mathrm{~m} / \mathrm{s}$ \\
\hline
\end{tabular}


Test 2, Run 1 used a width polynomial constant coefficient of 50 meters. The results were very similar to those of Test 1 . The fused results correctly depicted a flat layer boundary at 100 mbgs (Figure 5). The velocities matched the values from Test 1 as well.

Test 2, Run 2 was made with a width polynomial constant coefficient of 100 meters, but the nonconstant coefficients for the second-order polynomial were set to 50 meters. Although the layer boundary in the fused results averages close to $100 \mathrm{mbgs}$ at the center of the grid, it dips toward the corners of the grid, to a maximum of $120 \mathrm{mbgs}$ at one corner (Figure 6). This layer boundary clearly exhibits the characteristics of a smoothly-dipping, second-order polynomial surface.

Test 2, Run 3 was made with velocity polynomial constant coefficients changed (skewed) to $500 \mathrm{~m} / \mathrm{s}$ and $15,000 \mathrm{~m} / \mathrm{s}$ for the top and bottom layers, respectively. The remaining parameters were the same as in the original earth model. Although the top-layer velocity converged close to $1,000 \mathrm{~m} / \mathrm{s}$, the bottom-layer velocity remained above $14,000 \mathrm{~m} / \mathrm{s}$ (Figure 7).

Test 2, Run 4 was the same as Run 3 except the overall velocity polynomial sigmas were increased to $250 \mathrm{~m} / \mathrm{s}$ and $2,500 \mathrm{~m} / \mathrm{s}$ (from $50 \mathrm{~m} / \mathrm{s}$ ) for the top and bottom layers, respectively. The fused results show a top layer velocity close to $1,000 \mathrm{~m} / \mathrm{s}$ and a horizontally varying bottom layer velocity, which ranges from close to $10,000 \mathrm{~m} / \mathrm{s}$ in the center of the grid to near $15,000 \mathrm{~m} / \mathrm{s}$ in the corners (Figure 8).

In Test 2 , Run 5 , the initial earth model velocity polynomial constant coefficients were left at $500 \mathrm{~m} / \mathrm{s}$ and $15,000 \mathrm{~m} / \mathrm{s}$, the overall velocity polynomial sigmas were returned to $50 \mathrm{~m} / \mathrm{s}$, and the constant-term sigmas for the velocity polynomial were increased to $300 \mathrm{~m} / \mathrm{s}$ and 2500 $\mathrm{m} / \mathrm{s}$ for the top and bottom layers, respectively. The top and bottom layer velocities converged correctly on $1,000 \mathrm{~m} / \mathrm{s}$ and $10,000 \mathrm{~m} / \mathrm{s}$ for this run (Figure 9 ).

The results from this series of tests illustrate the effects of starting with an initial earth model that is significantly different from the measurement data for a simple, one-dimensional earth. The data fusion consistently converged on a layer boundary depth close to 100 meters for this test, but the fused layer boundary surface retained a 3-dimensional structure when the initial width polynomial was given large first- and second-order coefficients. When the initial earth model layer velocities were skewed, the top layer velocity consistently converged close to the correct value of $1,000 \mathrm{~m} / \mathrm{s}$, but the bottom layer velocity remained elevated unless the polynomial constant coefficient sigma was increased significantly. The overall velocity polynomial sigma seemed to control the spatial variance of the velocity rather than large shifts in the overall velocity value.

\subsection{Test 3}

The purposes of Test 3 were to analyze the effects of an aberrant well pick in the data set on the final fusion results and to determine how well the data was honored for different earth model parameter values.

For Test 3 the value for the northwest well pick (well 1-1) was reduced to 50 mbgs in the well measurement data file, while every other well pick was kept the same. The base earth model was used in conjunction with the altered measurement data set for a data fusion run and then different parameters in the earth model were adjusted for four additional runs. The earth model parameters that were varied include the width sigma and tau as well as the overall . earth model grid size. Table 3 lists the changes made to the earth model.

Test 3, Run 1 was made using the original earth model and measurement data set, except that the layer boundary at the northwest well pick (well 1-1) was reduced from 100 mbgs to 50 mbgs. The fused results converged on a flat layer boundary surface at $100 \mathrm{mbgs}$ and 
Table 3. Parameters in Earth Model Changed for Test 3

\begin{tabular}{||l|c|c|c|c|c|c||}
\hline Parameters Changed in Earth Model Initial Earth & Run 1 & Run 2 & Run 3 & Run 4 & Run 5 \\
\hline grid spacing & $50 \mathrm{~m}$ & Initial & $20 \mathrm{~m}$ & Initial & Initial & Initial \\
\hline $\begin{array}{l}\text { width polynomial exponential } \\
\text { correlation coefficient (tau) }\end{array}$ & $150 \mathrm{~m}$ & Initial & Initial & $50 \mathrm{~m}$ & Initial & $50 \mathrm{~m}$ \\
\hline width sigma & $3 \mathrm{~m}$ & Initial & Initial & Initial & $10 \mathrm{~m}$ & $10 \mathrm{~m}$ \\
\hline
\end{tabular}

exhibited no influence from the shallow well pick (Figure 10a); the data point was not honored by the data fusion. Three plots of normalized seismic reflection, seismic refraction, and well pick measurement data residuals versus grid " $y$ " position (N-S) are shown in Figures 10b, 10c, 10d. The residuals represent the difference between the actual measurement data value and the fused value at that point. The residuals are normalized by dividing the residual by the assigned sigma for that data point. Figure $10 \mathrm{~b}$ shows that the seismic reflection- and seismic refraction-normalized residuals, respectively, are less than the absolute value of one. All of the well-pick-normalized residuals appear to be less than the absolute value of two (Figure 10d;. however, only two of the three well picks fall on the graph at the 300-meter grid " $y$ " spacing. The missing normalized well pick residual (from well $1-1$, ) falls off the graph; it has a value of -24.72 .

Test 3, Run 2 had the same input parameters as Run 1, except the grid spacing was reduced from 50 meters to 20 meters. The results were the same as Run 1 (Figure 11); the shallow well pick was not honored.

Test 3, Run 3 was made with tau reduced to from 150 to 50 meters. The grid spacing was returned to 50 meters. Once again, there was no evidence of the shallow well pick in the final results (Figure 12).

In Test 3, Run 4, the earth model width sigma was increased from 3 to 10 meters and tau was returned to 150 . The results were dramatically different from those of the previous three runs. A large high occurred in the layer boundary surface at the shallow well pick location (Figure 13). The peak is fairly symmetrical and reaches close to $50 \mathrm{mbgs}$. The surface anomaly extends in a radius at least two grid spacings from the peak. At the edge of the anomaly, a slight trough surrounds the base of the peak. Thus, the shallow well pick is honored when the width sigma is increased to 10 meters. (Note that none of the well postings match up with the well pick anomaly because of an incorrect shift in the well postings, the result of a software bug. A bug report was issued to CRC, but it was not fixed. Thus, this problem will be apparent in all plots that exhibit structure.)

In Test 3, Run 5, the width sigma was kept at 10 meters and tau was decreased to 50 meters. The results show a more pronounced peak that reaches higher than 40 mbgs and has a deeper trough at the base (Figure 14).

The results of the Test 3 runs show how well a single divergent data point is honored and which parameters in the earth model affect the results. In this test, only the width sigma had influence on how well the shallow data point was honored. When the width sigma was small, the errant data point was ignored, but, if it was increased significantly, the data point was honored.

\subsection{Test 4}

The purpose of Test 4 was to analyze the effect of several aberrant well picks on the final fusion results and to determine how well the data was honored for different earth model parameter values. Also of interest was the way that the fusion handled the gridding between the anomalous data. 
In Test 4 , the depth to the layer boundary for three scattered wells (1-3; 3-1, and 5-3) was reduced to $75 \mathrm{mbgs}$. The remainder of the data was left the same as in the base data set. As in Test 3, a fusion run was made with the base earth model, and then additional runs were made with different earth model parameters . The width polynomial order, sigma, and tau were the varied parameters for six additional runs. Table 4 lists these parameters.

\section{Table 4. Parameters in Earth Model Changed for Test 4}

\begin{tabular}{||l|c|c|c|c|c|c|c|c||}
\hline $\begin{array}{c}\text { Parameters Changed in Earth } \\
\text { Model }\end{array}$ & $\begin{array}{c}\text { Initial Earth } \\
\text { Model }\end{array}$ & Run 1 & Run 2 & Run 3 & Run 4 & Run 5 & Run 6 & Run 7 \\
\hline $\begin{array}{l}\text { width polynomial order } \\
\begin{array}{l}\text { width polynomial exponential } \\
\text { correlation coefficient (tau) }\end{array}\end{array}$ & 2 & Initial & 3 & Initial & Initial & Initial & Initial & Initial \\
\hline width sigma & $3 \mathrm{~m}$ & Initial & Initial & $10 \mathrm{~m}$ & $300 \mathrm{~m}$ & Initial & $10 \mathrm{~m}$ & $300 \mathrm{~m}$ \\
\hline \hline
\end{tabular}

Test 4, Run 1 was made with the original earth model and measurement data set except that three widely scattered well picks were reduced in depth to $75 \mathrm{mbgs}$. The fused results for this run exhibit three very broad, nondistinct anomalies in the layer boundary surface associated with the shallow well picks (Figure 15). On the west side of the grid, where one of the shallow well picks was located, there is a very low amplitude feature on the surface with a peak no higher than 90 mbgs. On the east side of the grid, where the other two errant well picks were located, there are two broad highs that reach $80 \mathrm{mbgs}$ at the northeast and southeast corners of the grid. The two highs are difficult to distinguish and, together, form an anomaly that covers half the grid.

Test 4, Run 2 used the same earth model parameters as Run 1 except a third-order width polynomial was used instead of a second-order one. As with the base earth model, the polynomial coefficients were all set to zero except the constant coefficient. There were no noticeable differences between the results of Run 1 and Run 2 (Figure 16).

Test 4, Run 3 incorporated the base earth model with the width polynomial tau reduced from 150 to 10 meters. The layer boundary surface highs associated with the shallow well picks are very distinct in the fused results, although the peaks do not reach higher than 80 mbgs (Figure 17). Each anomaly covers an area of only four grid spacings.

The width polynomial tau was increased to 300 meters in Test 4, Run 4. The fused results have a layer boundary surface with a negligible high on the west side of the grid and a very broad, nondistinct high reaching close to $80 \mathrm{mbgs}$ on the east side of the grid (Figure 18). The east side high gently slopes to the west taking up four grid spacings. It is not possible to distinguish two separate anomalies.

In Test 4 , Run 5 , the width sigma was increased to 10 meters and the tau was returned to its base value of 150 meters. The results from this set of parameters produced three higher amplitude peaks in the layer boundary surface that reached very close to $75 \mathrm{mbgs}$, the value of the shallow well picks (Figure 19). The three peaks are very distinct from each other, although the surface between the two peaks on the east side of the grid is elevated slightly above 100 mbgs.

Test 4, Run 6 had the same earth model parameters as Run 5 except the width tau was reduced to 10 meters. This change significantly reduced the spatial extent of the anomalies associated with the shallow well picks (Figure 20). The three individual peaks are much more isolated and reduced in amplitude from those when the tau was 150 meters. Run 6 showed some false structure in the layer boundary surface, which was not apparent in the previous runs.

The width tau was increased to 300 meters while the width sigma was kept at 10 meters for the Test 4, Run 7. The peaks in the layer boundary surface of the fused earth model are 
broader and smoother than those in runs 5 and 6 (Figure 21). The two peaks on the east side of the grid meld together to produce a large asymmetric high with a maximum amplitude of 80 mbgs.

The results of the Test 4 runs illustrate how varying parameters of the earth model width polynomial affected the data fusion results for a measurement data set with three widely scattered well picks that differed from the earth model. Specifically, the results were examined to determine how well the irregular well picks were honored, and what the shapes of the anomalies associated with those well picks were. The width polynomial parameters that had the greatest influence on those two aspects of the results were the overall sigma and tau. Even with the base earth model parameter settings, the effects of the shallow well picks were evident, unlike Test 3 , which had only one shallow pick that was evident in the visualization software. These results suggest that data fusion is more likely to honor aberrant well picks as their numbers increase, assuming they all share a common dissimilarity from the rest of the well picks. When sigma was increased, the aberrant well picks were better honored and when the tau was decreased the anomalies became more constricted and isolated from each other.

\subsection{Test 5}

The purpose of Test 5 was to determine how the number and density of data points influences the fusion process. In this test, the depth to the layer boundary for the entire western line of wells (1-1 through 1-5) was reduced to 75 mbgs. The earth model width sigma and tau were varied in four additional runs to analyze their effect on the results (Table 5).

Table 5. Parameters in Earth Model Changed for Test 5

\begin{tabular}{||l|c|c|c|c|c|c|}
\hline \hline Parameters Changed in Earth Model & Initial Earth Model & Run 1 & Run 2 & Run 3 & Run 4 & Run 5 \\
\hline $\begin{array}{l}\text { width polynomial exponential } \\
\text { correlation coefficient (tau) }\end{array}$ & $150 \mathrm{~m}$ & Initial & $10 \mathrm{~m}$ & $300 \mathrm{~m}$ & $10 \mathrm{~m}$ & $300 \mathrm{~m}$ \\
\hline width sigma & $3 \mathrm{~m}$ & Initial & Initial & Initial & $10 \mathrm{~m}$ & $10 \mathrm{~m}$ \\
\hline
\end{tabular}

Test 5, Run 1 was performed using the base earth model inputs with the altered data set. The data fusion results exhibit an extensive linear high in the layer boundary surface that covers the entire western half of the grid (Figure 22). All five shallow well picks were honored.

Tau was reduced to from 150 to 10 meters for Test 5 , Run 2 . The high in the layer boundary surface in the final earth model appears sharper than Test 5, Run 1 (Figure 23). However, a false high occurs in the surface in the northeast part of the grid and the surface slopes to at least 105 mbgs at the southeast corner of the grid.

Test 5, Run 3 was executed with a width tau of 300 meters. This run produced a smoother, more extensive anomaly in the layer boundary surface (Figure 24) than occurred in Test 5, Run 2.

Test 5, Run 4 had both the width sigma and tau set to 10 meters. The high in the layer boundary surface is distinct for this case, but there false structure occurs in the surface as well (Figure 25).

The tau was increased to 300 meters and the sigma was left at 10 meters for Test 5 , Run 5 . This change eliminated most of the false structure in the layer boundary surface (as shown in Run 4) and the high is better confined than in Run 3 (Figure 26).

The results from the Test 5 runs illustrate that data fusion will honor a series of adjacent aberrant well picks, even if the width sigma in the user-defined initial earth model is relatively small. These results are very different from Test 3 , where there was only one aberrant well 
pick. In Test 3, the shallow well pick was not honored unless the width sigma was quite large. Thus, if there are small-scale abnormalities in the measurement data that are considered real, and the user wants to honor those data, the user must be careful to select a large enough sigma for the earth model polynomials. However, this concern is not so critical if the abnormalities are of a larger scale and supported by many data points.

\subsection{Test 6}

The performance of CRC's data fusion software is sensitive to the distribution of data points. The software is designed to work most efficiently (i.e., faster) when data is aligned in north-south columns. The user can adjust the data to meet this criterion by adjusting the rotation of the fusion grid. The purpose of Test 6 was to determine the effect in computational time that would arise if the data could not be all be aligned in a north-south manner.

The location of the seismic reflection lines were changed for Test 6 . The western line was removed and a new east-west (E-W) trending line was added to the middle of the grid intersecting the third line of wells. The seismic travel times associated with the new reflection line matched those of the other reflection line. All the measurement data, as well as all the earth model parameters, used in Test 6 were the same as the original earth section.

Two fusion runs were made with this data set, one with no grid rotation and one with a 45 degree grid rotation. The rotated grid had to be expanded by two columns and rows to fit the data (Figure 27).

The run time for the unrotated grid was 38 seconds, more than twice as long as the run time where both seismic lines were north-south rather than perpendicular. The run time for the rotated grid was 76 seconds. In this case rotating the grid 45 degrees increased the $x$ extent of the seismic data by a factor of the square root of 2 . This fact, along with the larger grid size, accounts for the increased data fusion run time.

The results of Test 6 indicate that the spatial distribution of data and grid size can have a negative effect on computer run times. Fusion runs for real data sets at the Hanford Site can take hours to complete, so these effects can be significant with potential fourfold increases in run time. Thus, a user of CRC's data fusion software should be very aware of the effects of grid size and spatial distribution, and mitigate them by appropriate use of grid rotation.

\subsection{Test 7}

The purpose of Test 7 was to determine how data fusion software would respond to differences in data density and to observe the effect of changing measurement sigmas on the fused results. That is, how will the software balance biased, high-density seismic data with coincident unbiased, sparsely spaced well data..

Test 7 consisted of running the original data set with the addition of a third reflection line that trends $\mathrm{E}-\mathrm{W}$ and runs through the center of the grid (overlapping three wells). All the travel time picks in the E-W line had a bias of negative 50 milliseconds. Three fusion runs were conducted.

The input to Test 7, Run 1 consisted of the base earth model and the base measurement data set with the addition of a third seismic reflection line. The fusion results have a smallamplitude, narrow, linear ridge below the location of the biased reflection line (Figure 28a). Normalized residual plots for the measurement data clearly show the effect of the biased E-W reflection line on the normalized reflection residuals (Figure 28b). The absolute value of the unbiased reflection line residuals starts to increase 100 meters to either side of the biased reflection line and peak where the unbiased and biased lines cross. Most of the biased reflection line residuals are high as well. For the refraction and well pick data, the refraction 
residuals show little effect from the biased reflection line (Figure 28c), but the three wells lying on the biased reflection have elevated normalized residuals (Figure 28d).

Test 7, Run 2 used the same setup as Run 1 except that the width sigma was increased to 10 meters. The results differ from those in Run 1 in that the ridge in the layer boundary surface has a slightly higher amplitude and is better defined (Figure 29).

For Test 7, Run 3, the same earth model and measurement data run were used as in Run 2, except the measurement sigmas of the biased travel times were also increased from 3 to 10 milliseconds. In this case the ridge anomaly in the boundary surface was reduced to three disconnected, buffered highs separated where the N-S well and seismic lines intersect the E-W line (Figure 30). A false high along the northern edge of the grid occurred in Run 2 as well.

The results from Test 7 runs illustrate that aberrant, high-density seismic data are honored more than consistent, low-frequency well data by data fusion, unless the measurement sigma on the aberrant seismic data is increased significantly. 


\subsection{CONCLUSIONS}

PNL performed a series of seven tests on the Hanford DFW using a simple artificial data set to qualitatively analyze the sensitivity of the data fusion software to various input parameters. The earth model contains a set of parameters that the user selects before making a data fusion run. In addition, the user must assign a sigma to every measurement data value.

Several parameters in the earth model had a large influence on the data fusion results: 1) width sigma, 2) exponential correlation coefficient (tau), and 3) coefficient sigmas for the polynomial. The width sigma and tau seem to control, respectively, the allowable amplitude and "smoothness" of spatial variability of the fused results, respectively The polynomial coefficient sigmas control the allowable variability in that particular coefficient. Specifically, the constant coefficient sigma determines the allowable shift in the polynomial surface. The values of the width sigma and tau can have a major effect on the results, if the measurement data have high spatial variability. The larger the width sigma, the better the amplitude of the spatial variability is honored; the smaller the tau, the better small scale spatial changes are honored. The polynomial constant coefficient sigma can have a major effect on the data fusion results if the starting earth model is significantly skewed, or offset, from the measurement data. In such a scenario, the larger the constant coefficient sigma, the better the polynomial surface converges on the location of the surface predicted by the measurement data.

The measurement data sigma represents the actual standard deviation of that particular measurement. The magnitude of these sigmas has the greatest influence on how groups of measurement data are honored by data fusion relative to other data points. However, the measurement sigma does not seem to affect how well a single data point is honored relative to a large group of other data points. In the tests, even assigning a very low sigma to a single aberrant measurement data point had little effect on how well the measurement value was honored by the data fusion, if it was in the vicinity of a large number of other data points that differed from it.

This sensitivity analysis of data fusion using a synthetic data set affirmed the need for a wellinformed user running the data fusion software. This user should recognize that the values given to the numerous user-defined parameters can have a significant effect on the results and should be aware of what effect these values will produce. Ideally, the user should perform a sensitivity analysis for every problem by varying the input parameters slightly up and down and observing how much the results change. In general, if the user wants data fusion to honor the measurement data as closely as possible, without exerting predefined controls on it, the initial earth model sigmas should be set relatively high and the taus should be set relatively low. 
FIGURE 1. Synthetic Data Set and Earth Model Used for Data Fusion Sensitivity Analysis
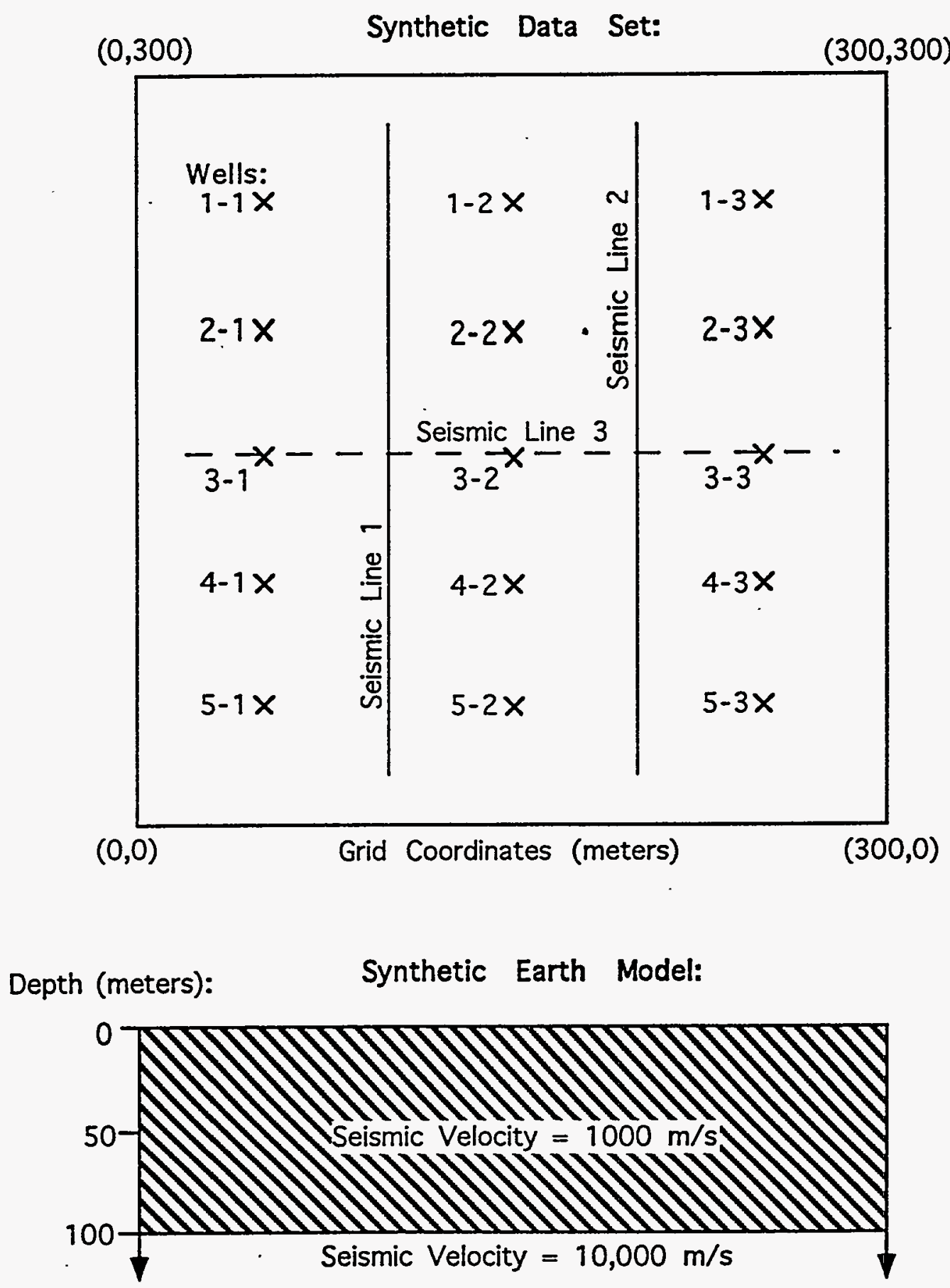
FIGURE 2. DFW Earth Model Width Polynomial Coefficient Specification Window 


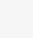




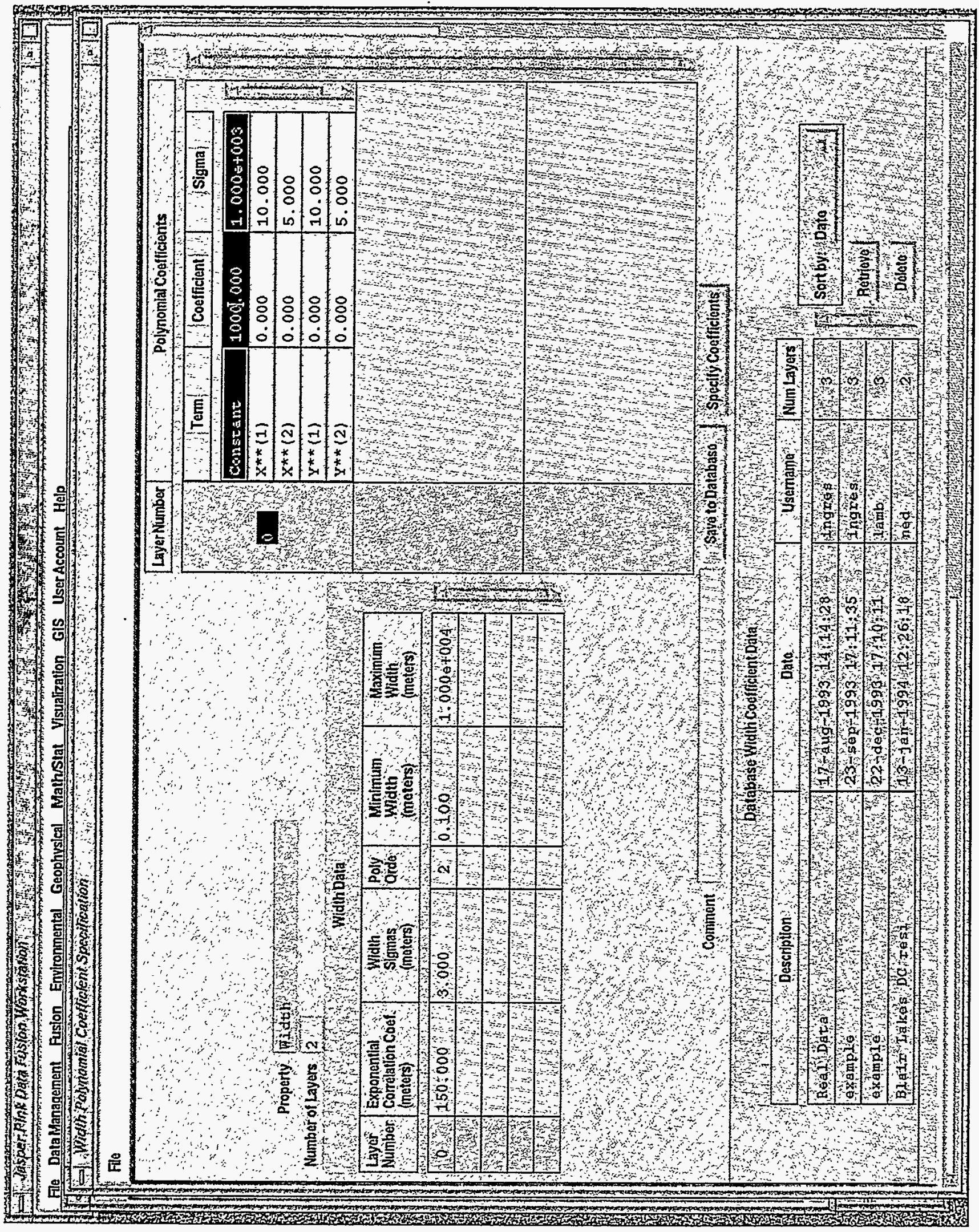


$\therefore \ldots \quad$. 
FIGURE 3. DFW Earth Model Velocity Polynomial Coefficient Specification Window 
.. 


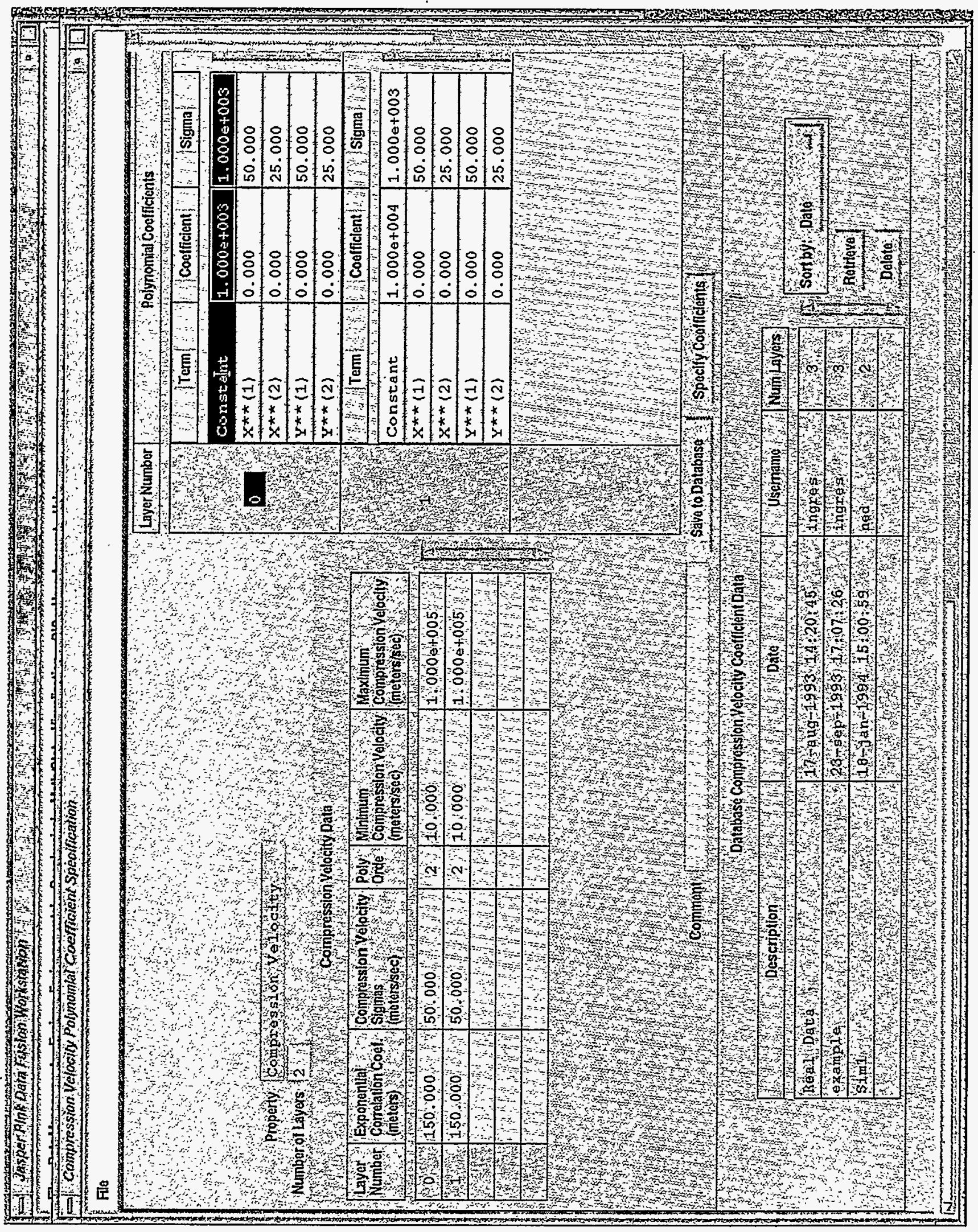


FIGURE 4. Test 1 Results 



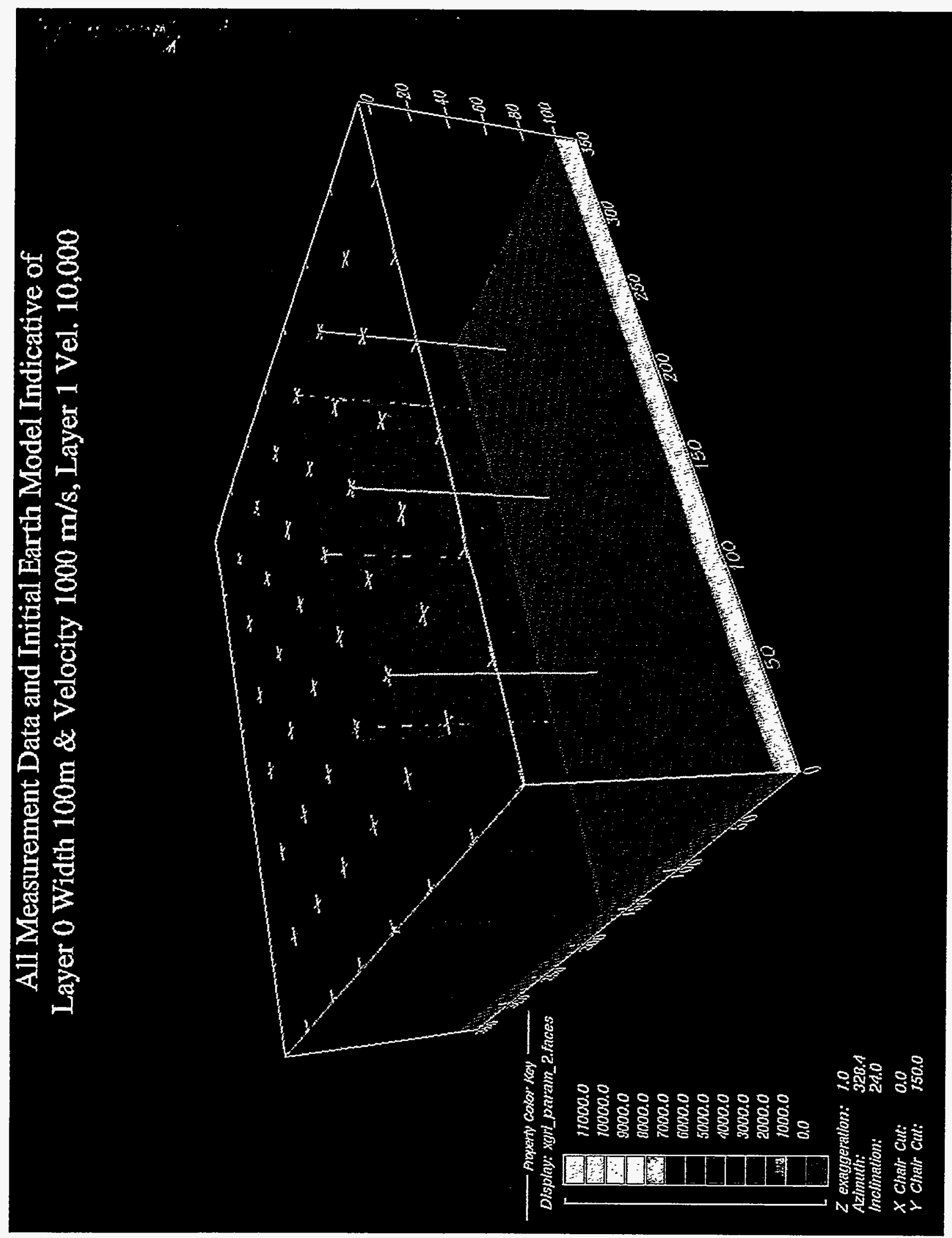


FIGURE 5. Test 2, Run 1 Results 
$\ldots$ 


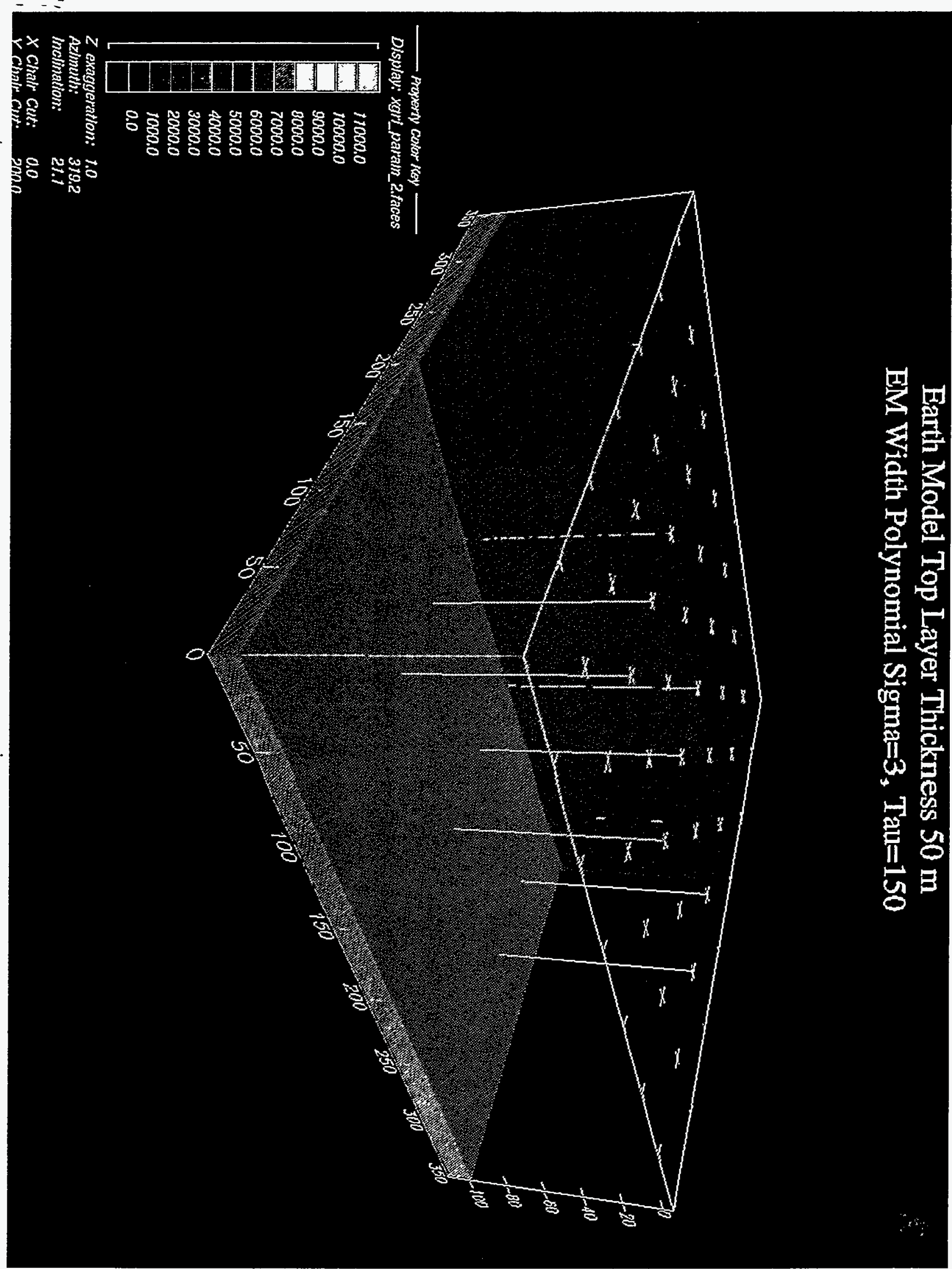



- 
FIGURE 6. Test 2, Run 2 Results 



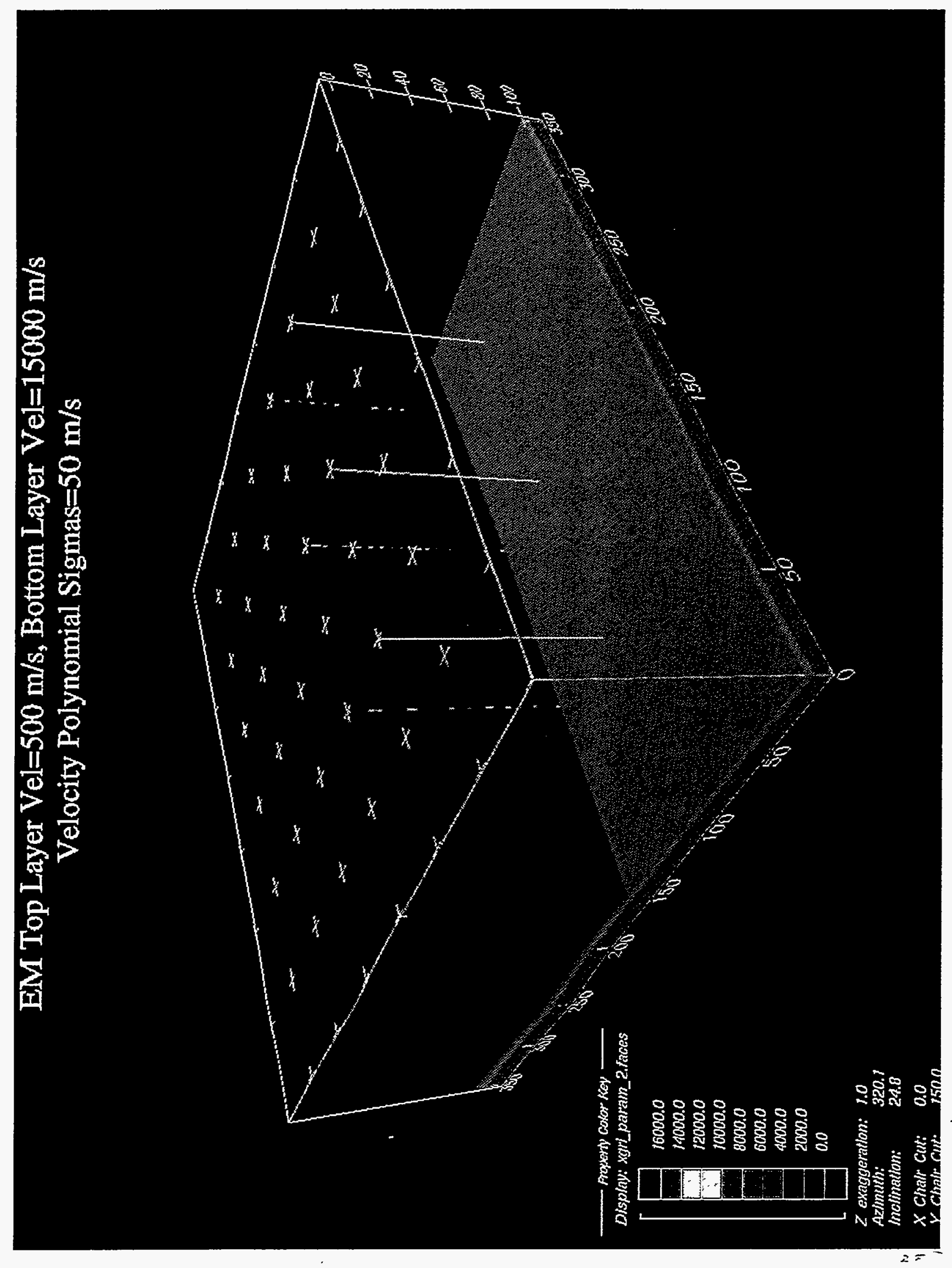




\section{FIGURE 7. Test 2, Run 3 Results}



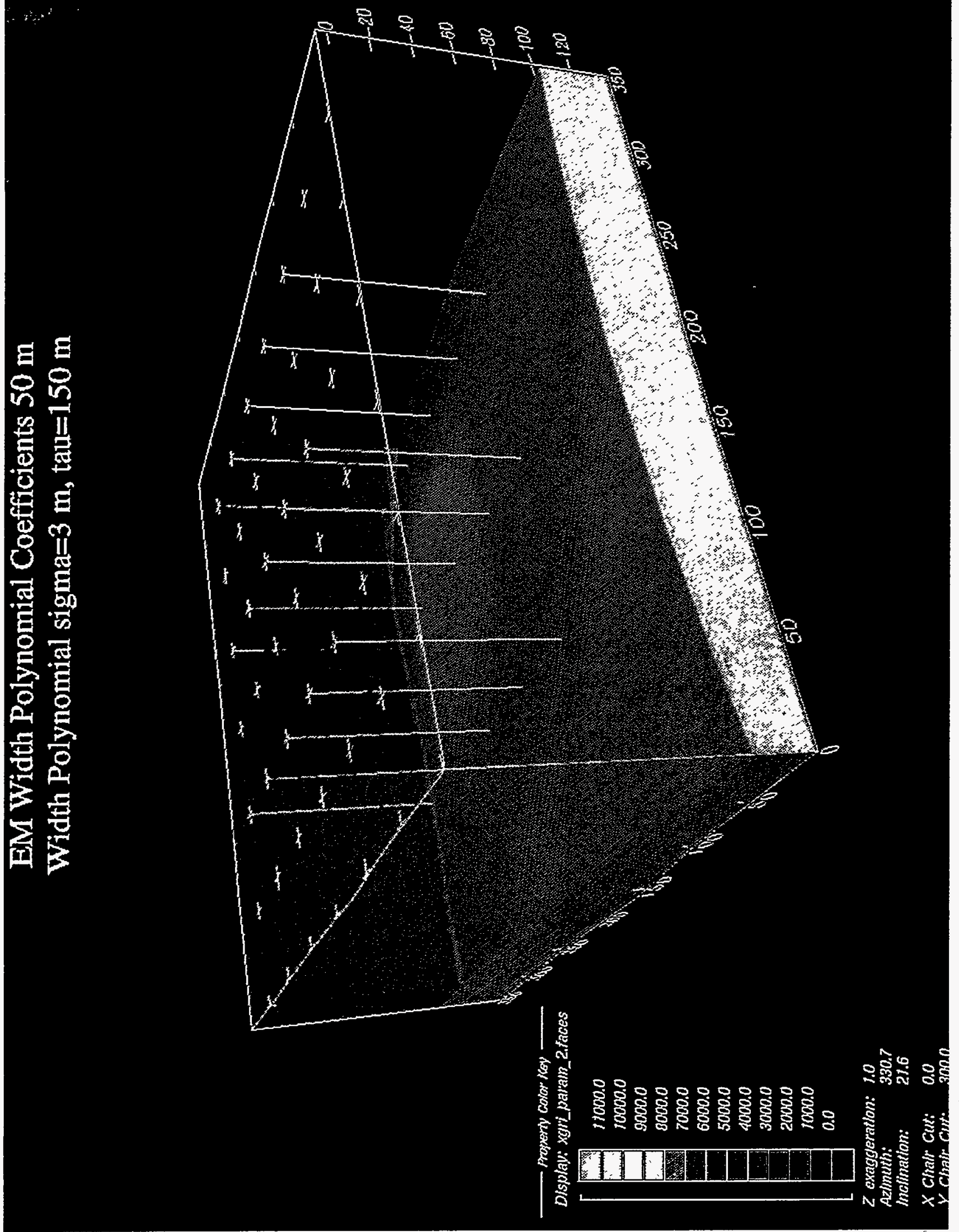
FIGURE 8. Test 2, Run 4 Results 
$+\ldots$

. 
EM Top Layer Vel $=500 \mathrm{~m} / \mathrm{s}$, Bottom Layer Vel $=15000 \mathrm{~m} / \mathrm{s}$

Vel. Polynomial SigmaTop $=250 \mathrm{~m} / \mathrm{s}$, Sigma Bottom $=2500 \mathrm{~m} / \mathrm{s}$

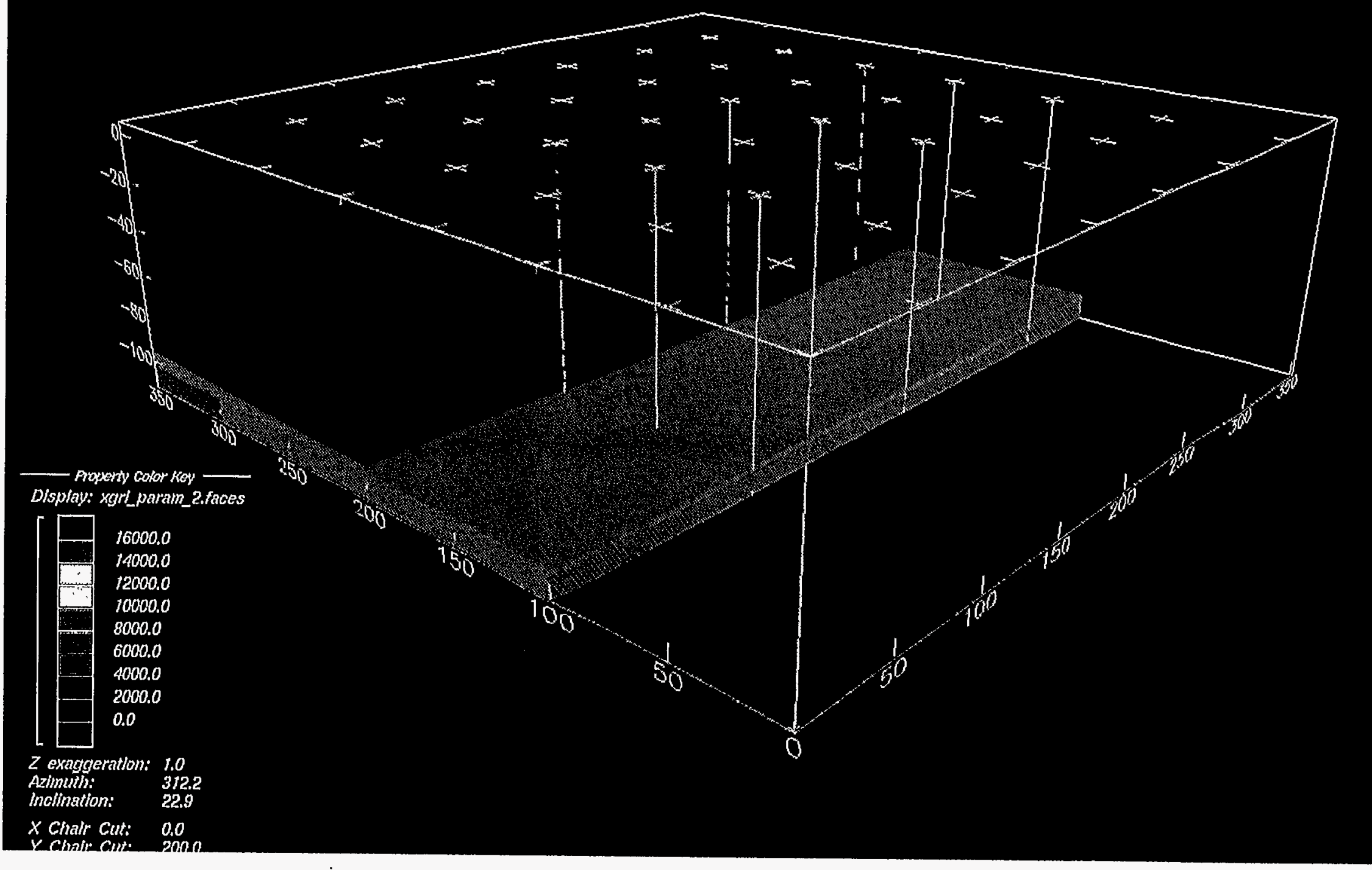


FIGURE 9. Test 2, Run 5 Results 


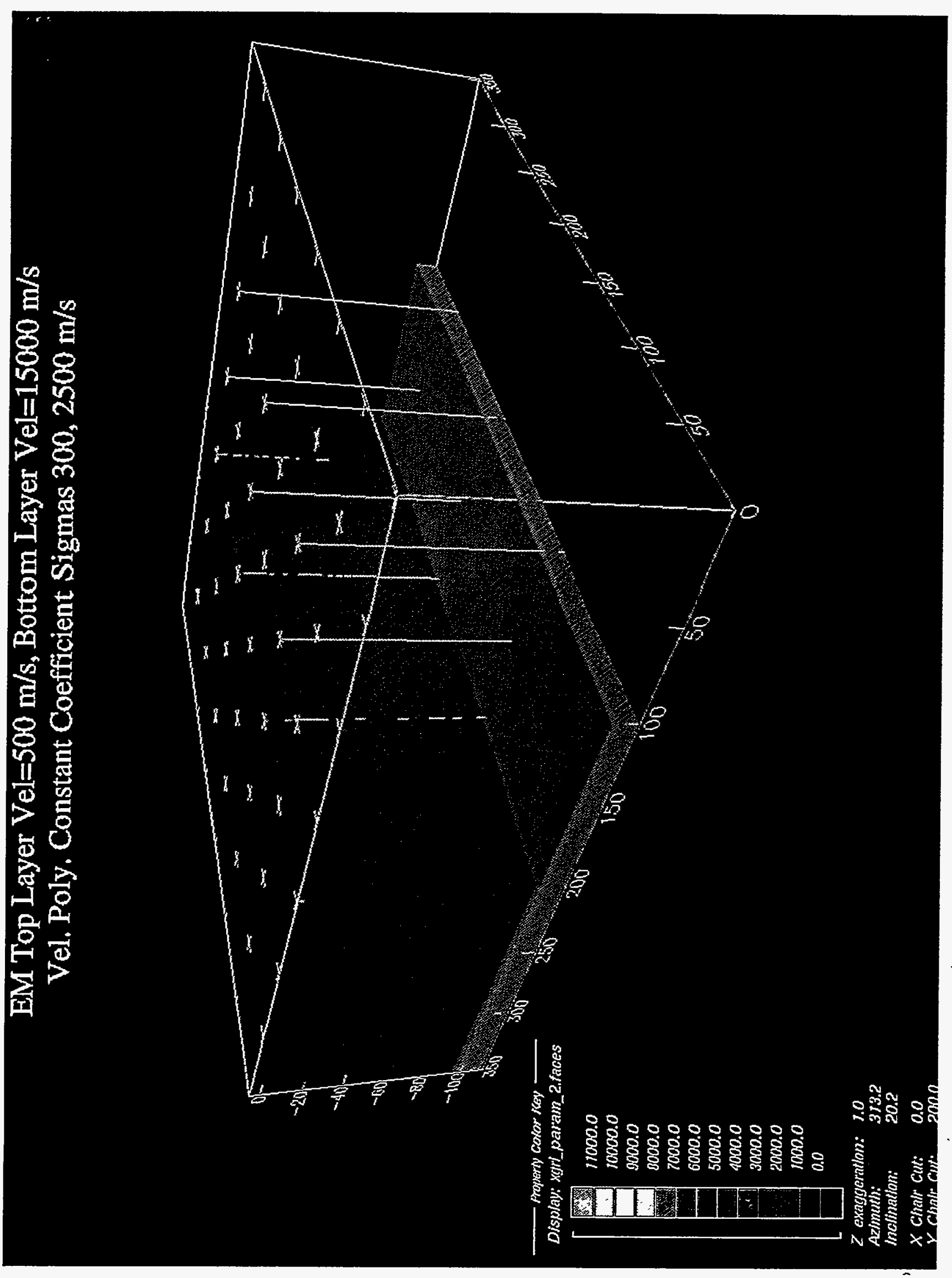




\section{FIGURE 10a. Test 3, Run 1 Results}


$\ldots \ldots$ 


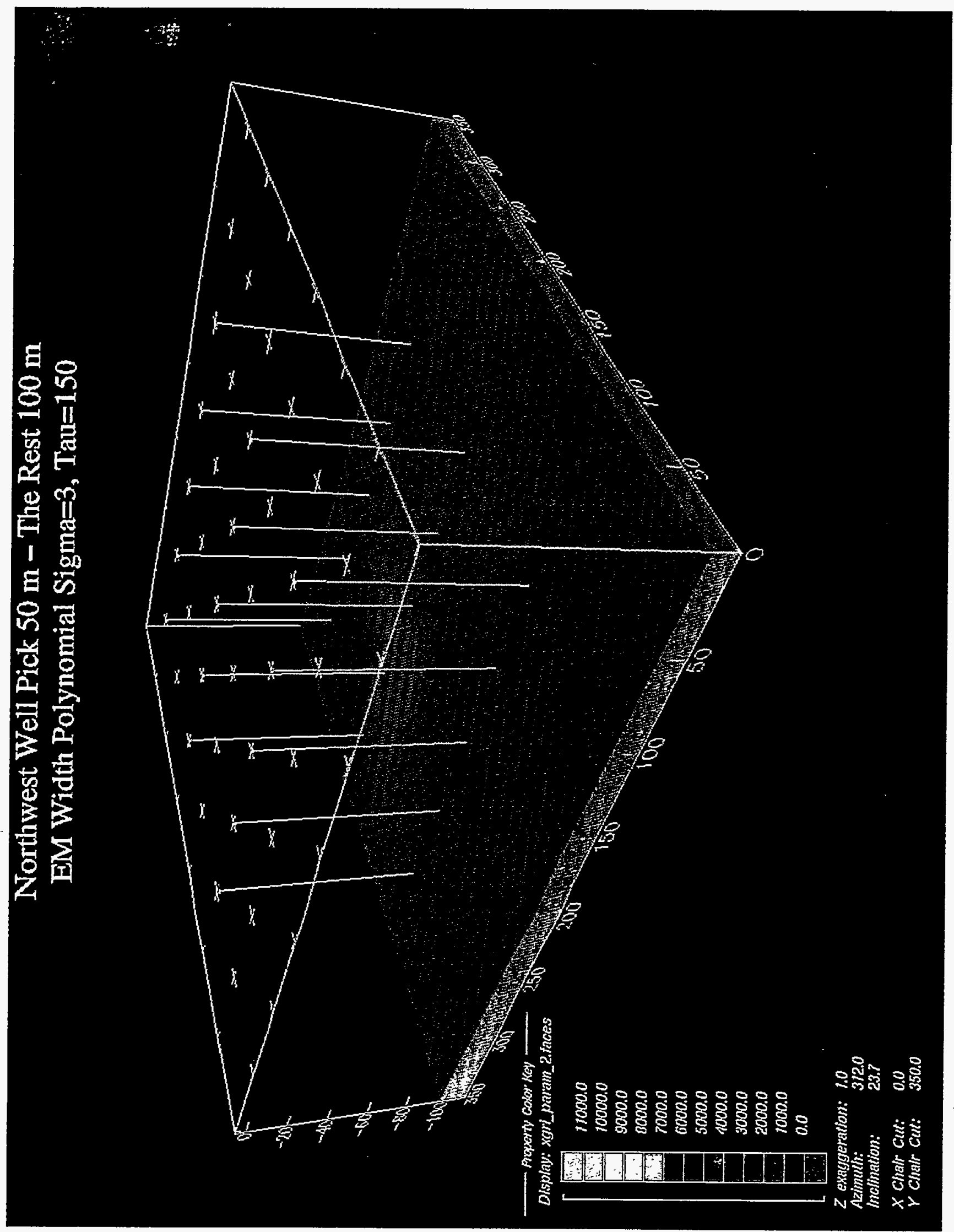




\section{FIGURE 10b. Test 3, Run 1 Normalized Reflection Residuals Plot}




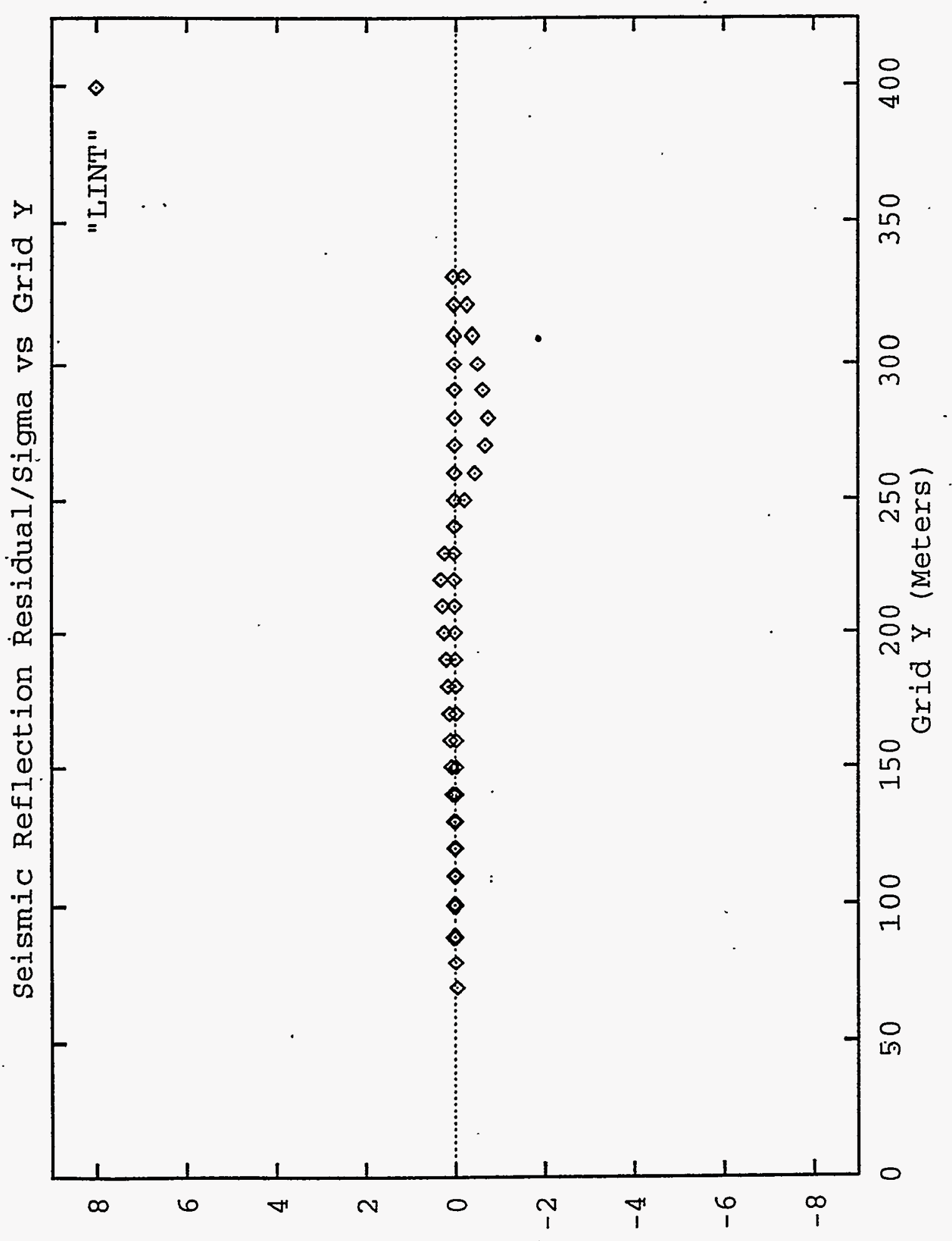

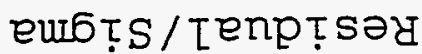


$\ldots$

• 
FIGURE 10c. Test 3, Run 1 Normalized Refraction Residuals Plot 
$\begin{array}{ll} \\ -\end{array} \ldots+\ldots$

. 


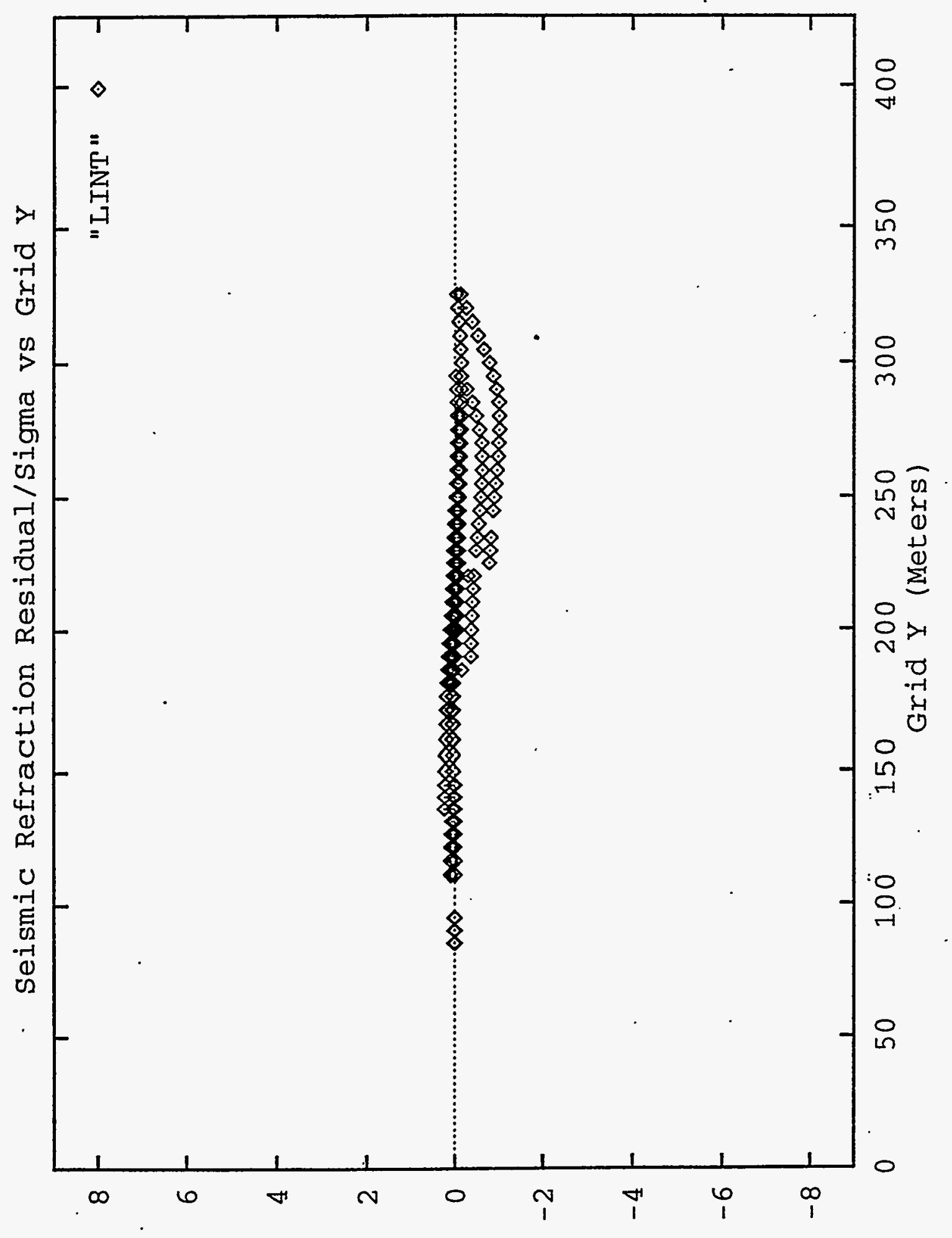

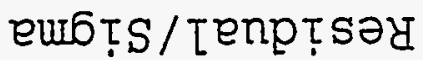


- _ - 
FIGURE 10d. Test 3, Run 1 Normalized Well Pick Residual Plot 
-

$\ldots$ 


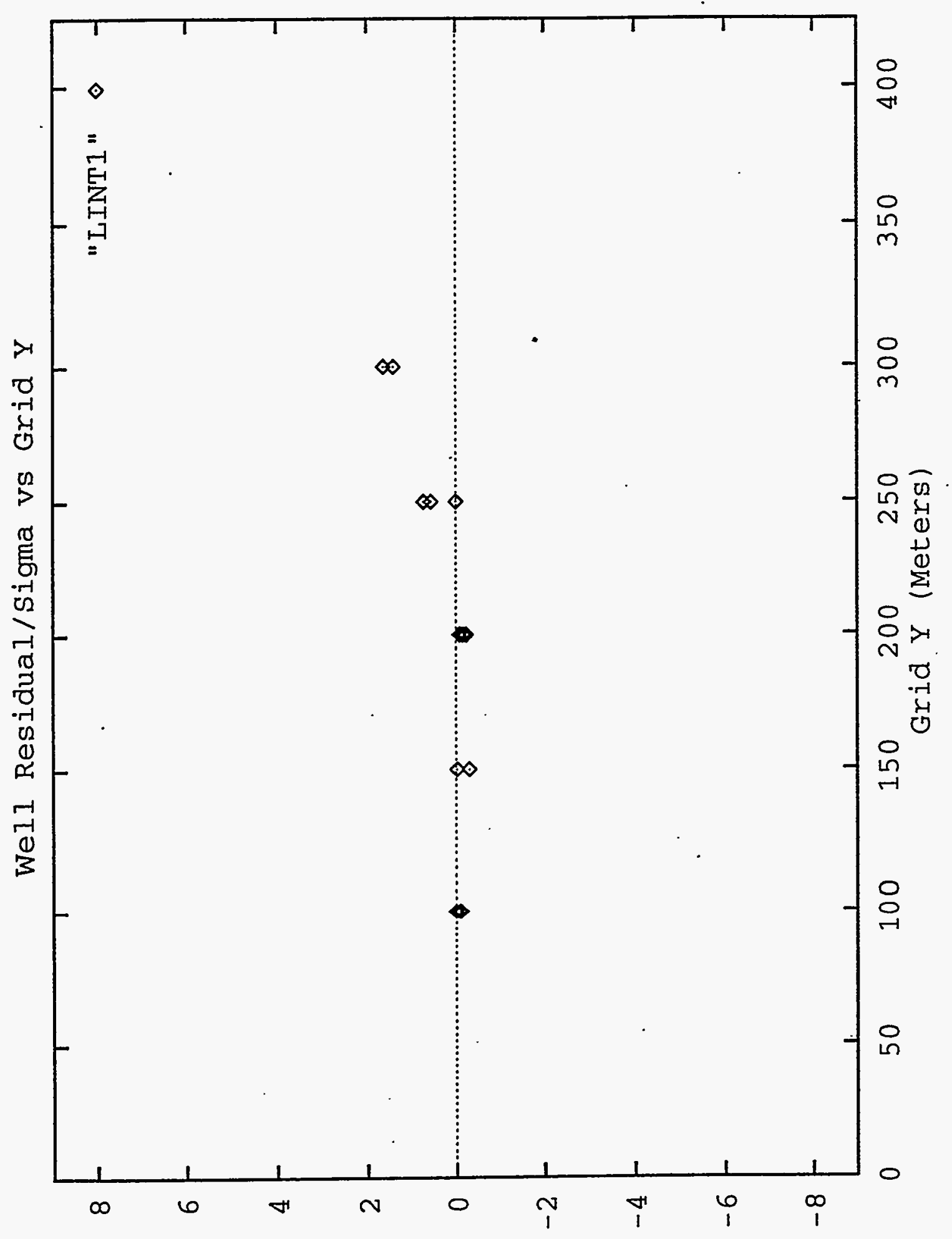

eứț / Tenpțsəy 
$\ldots$ 
FIGURE 11. Test 3, Run 2 Results 



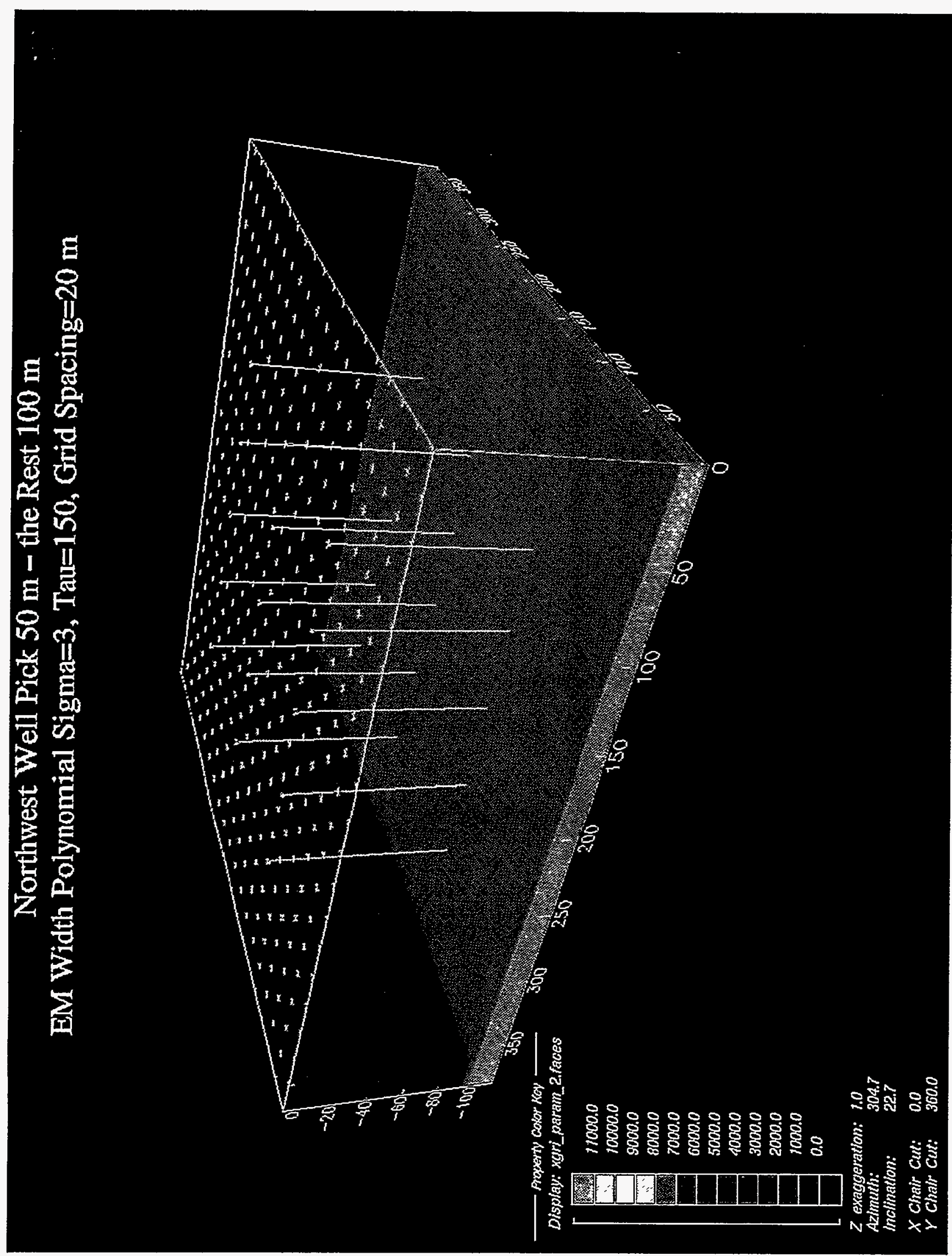


FIGURE 12. Test 3, Run 3 Results 
. . .

-

. 


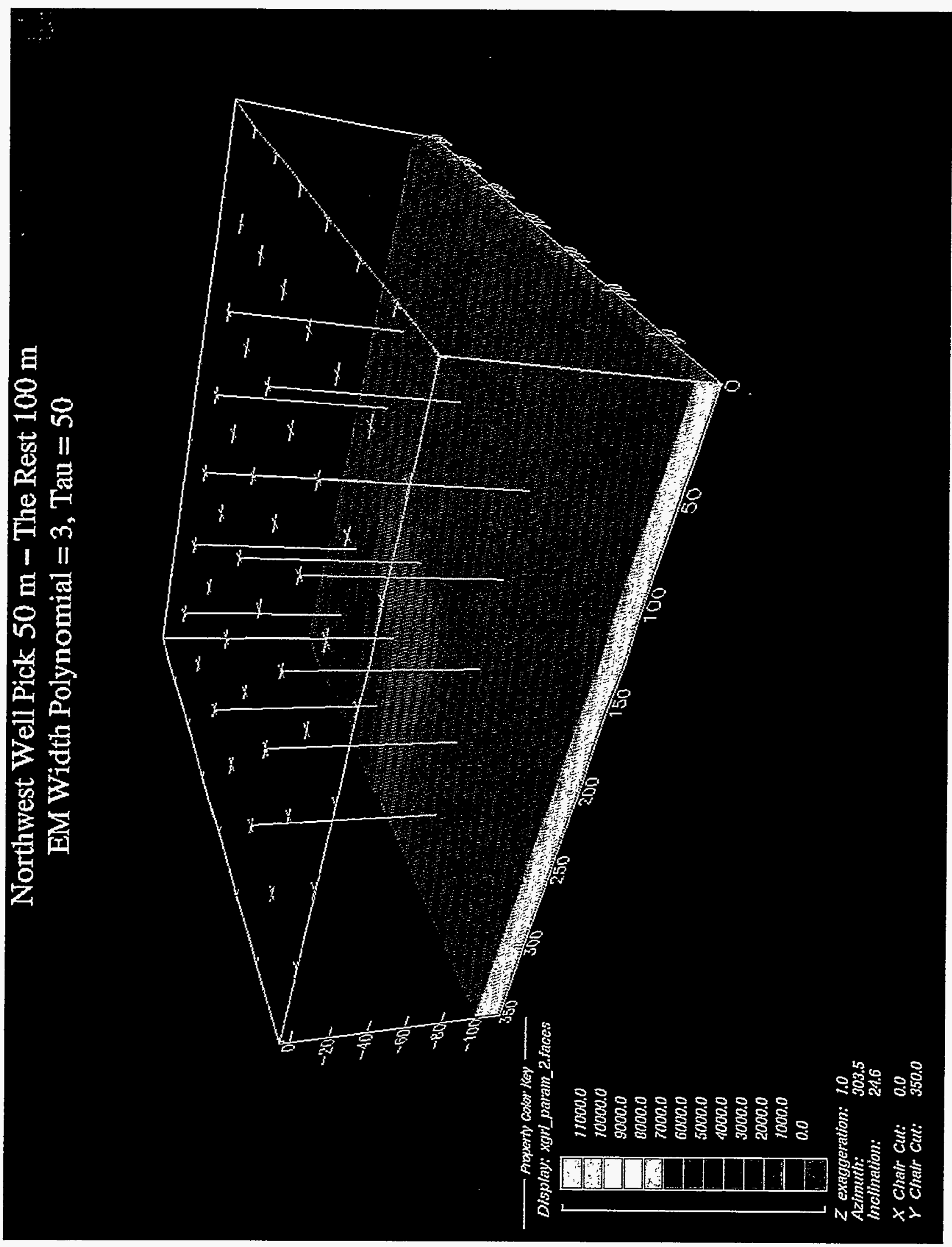


_... . .

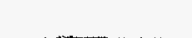

( _.............. 
FIGURE 13. Test 3, Run 4 Results 
. 


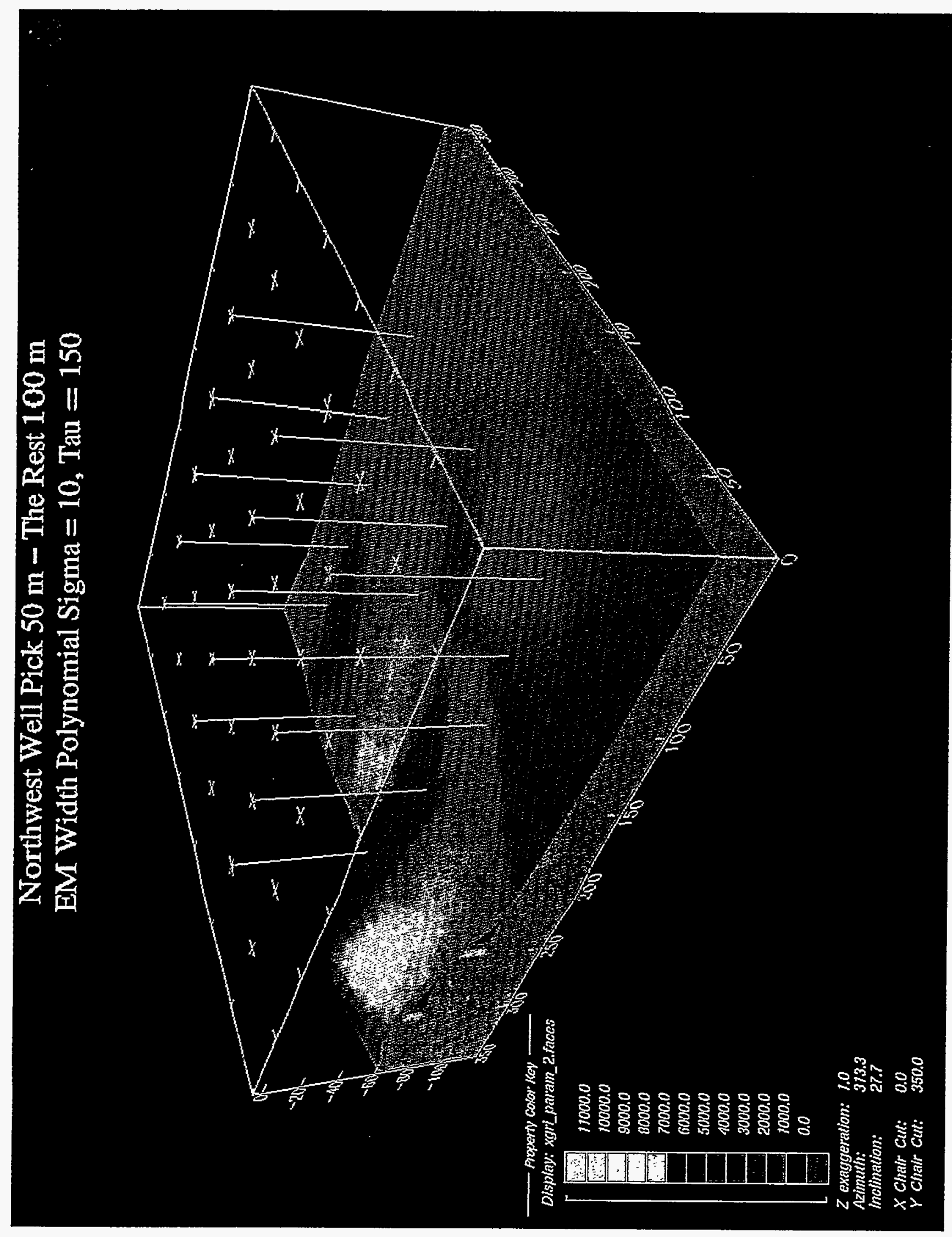


FIGURE 14. Test 3, Run 5 Results 
.

.......... 


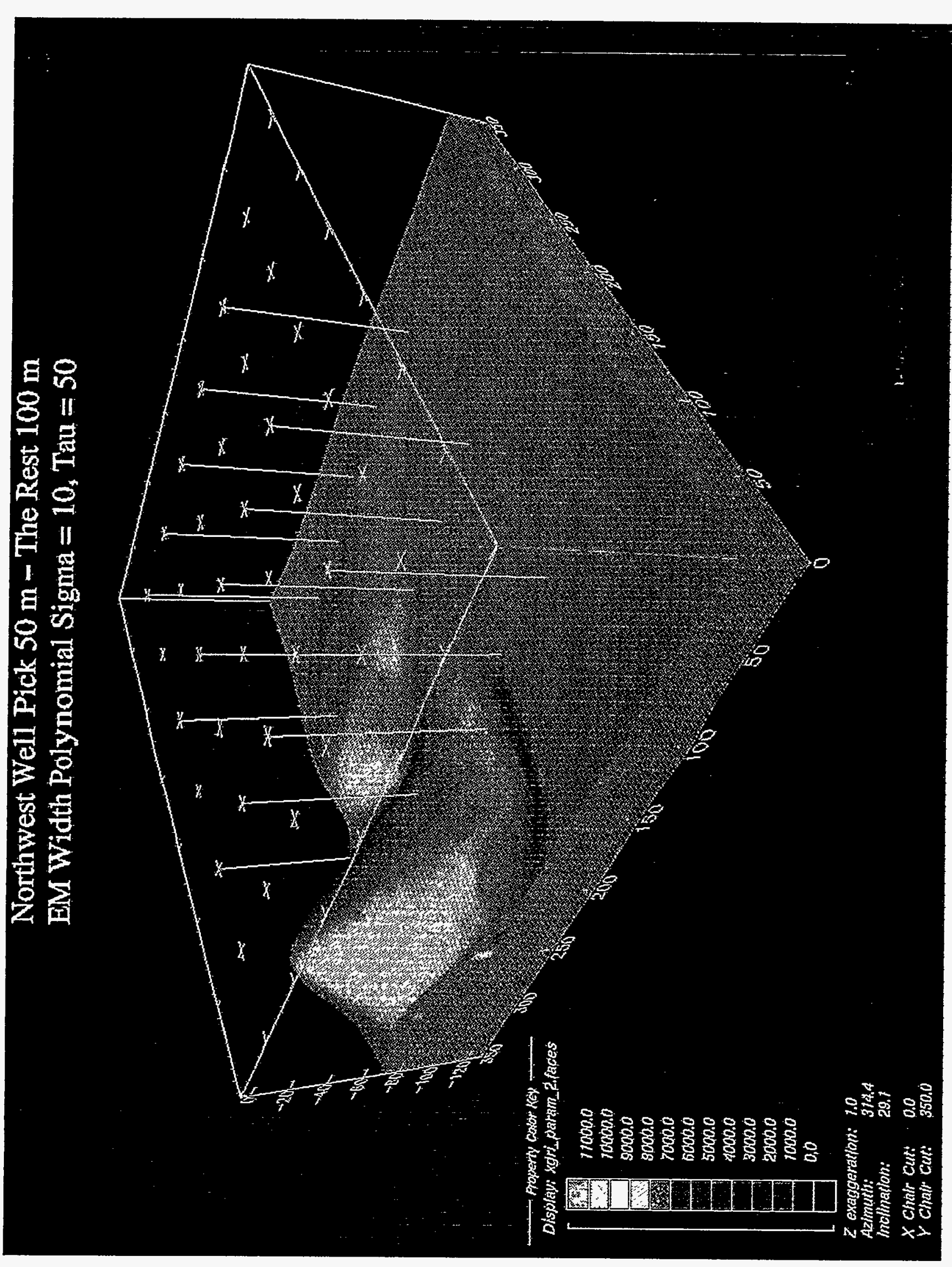


FIGURE 15. Test 4, Run 1 Results 


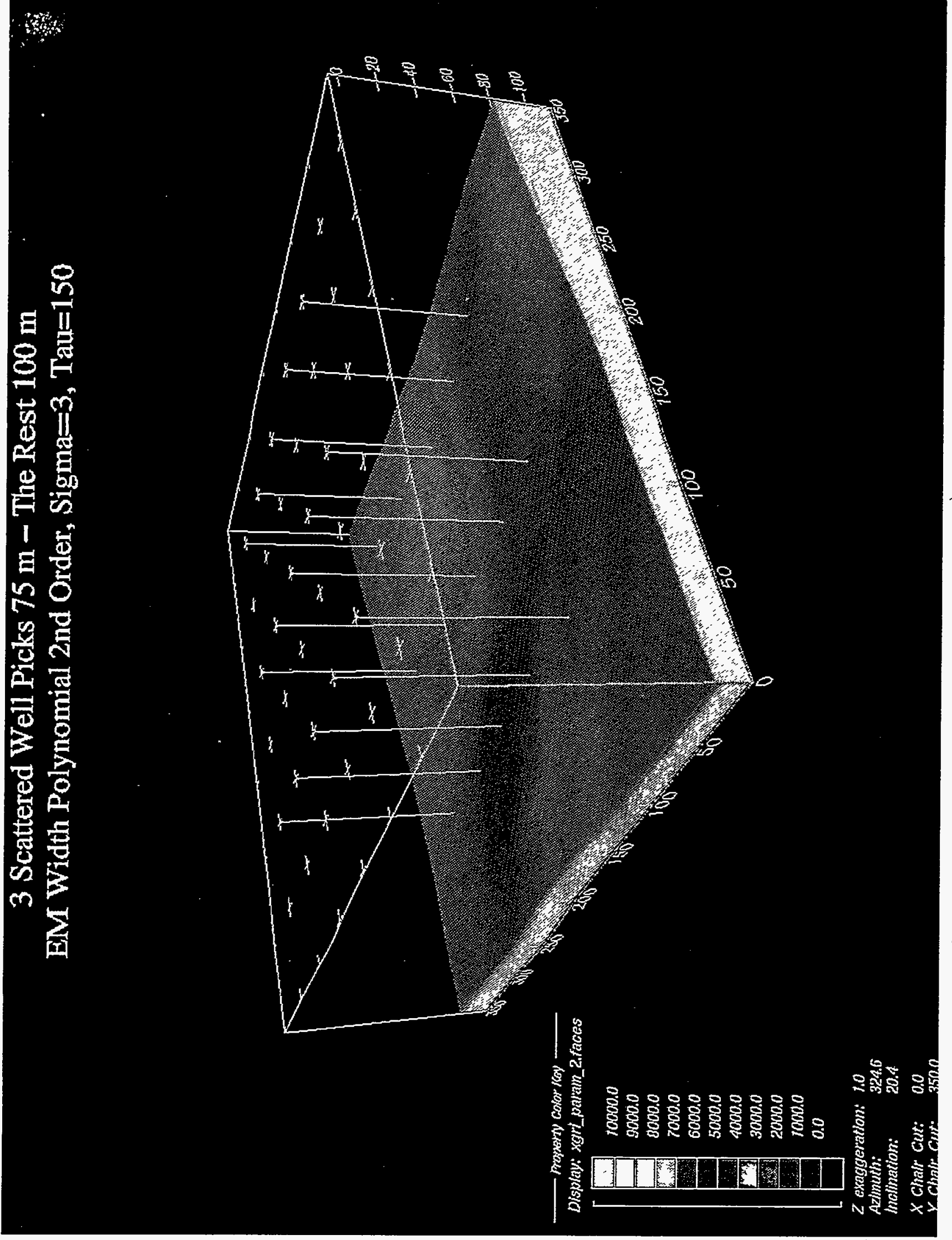


FIGURE 16. Test 4, Run 2 Results 


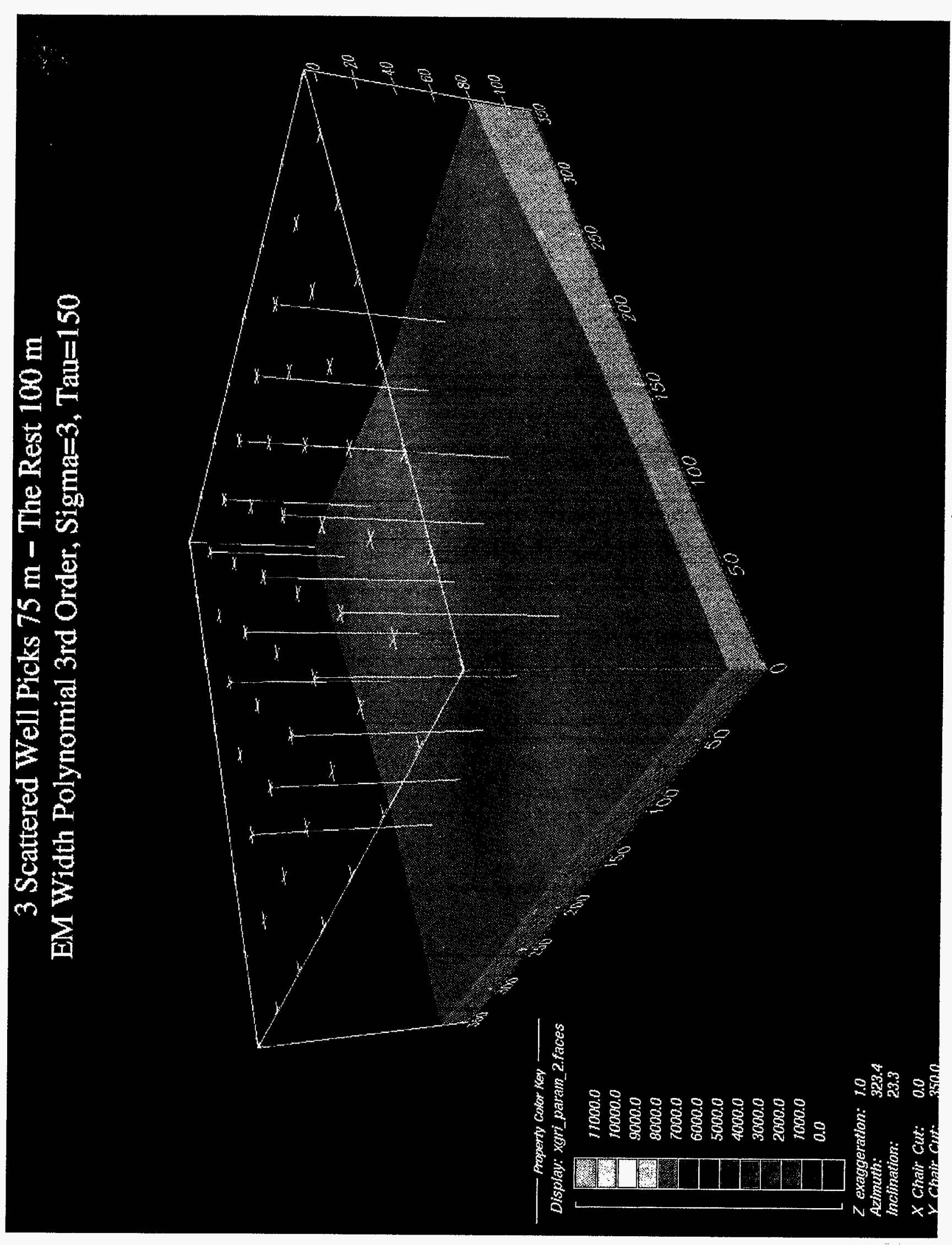




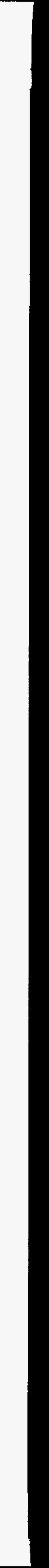


FIGURE 17. Test 4, Run 3 Results 


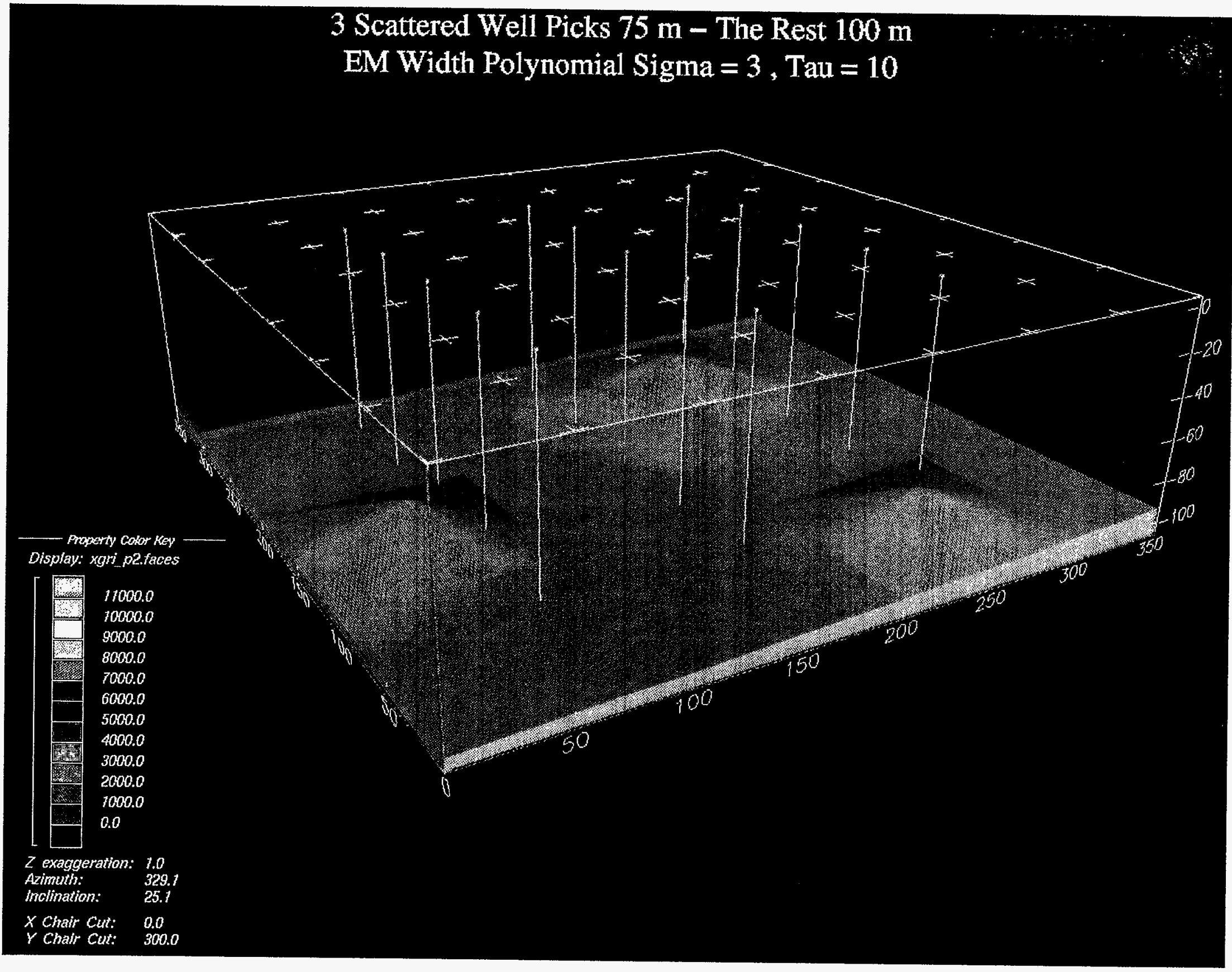




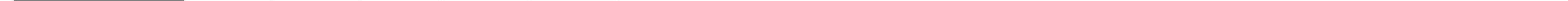


FIGURE 18. Test 4, Run 4 Results 


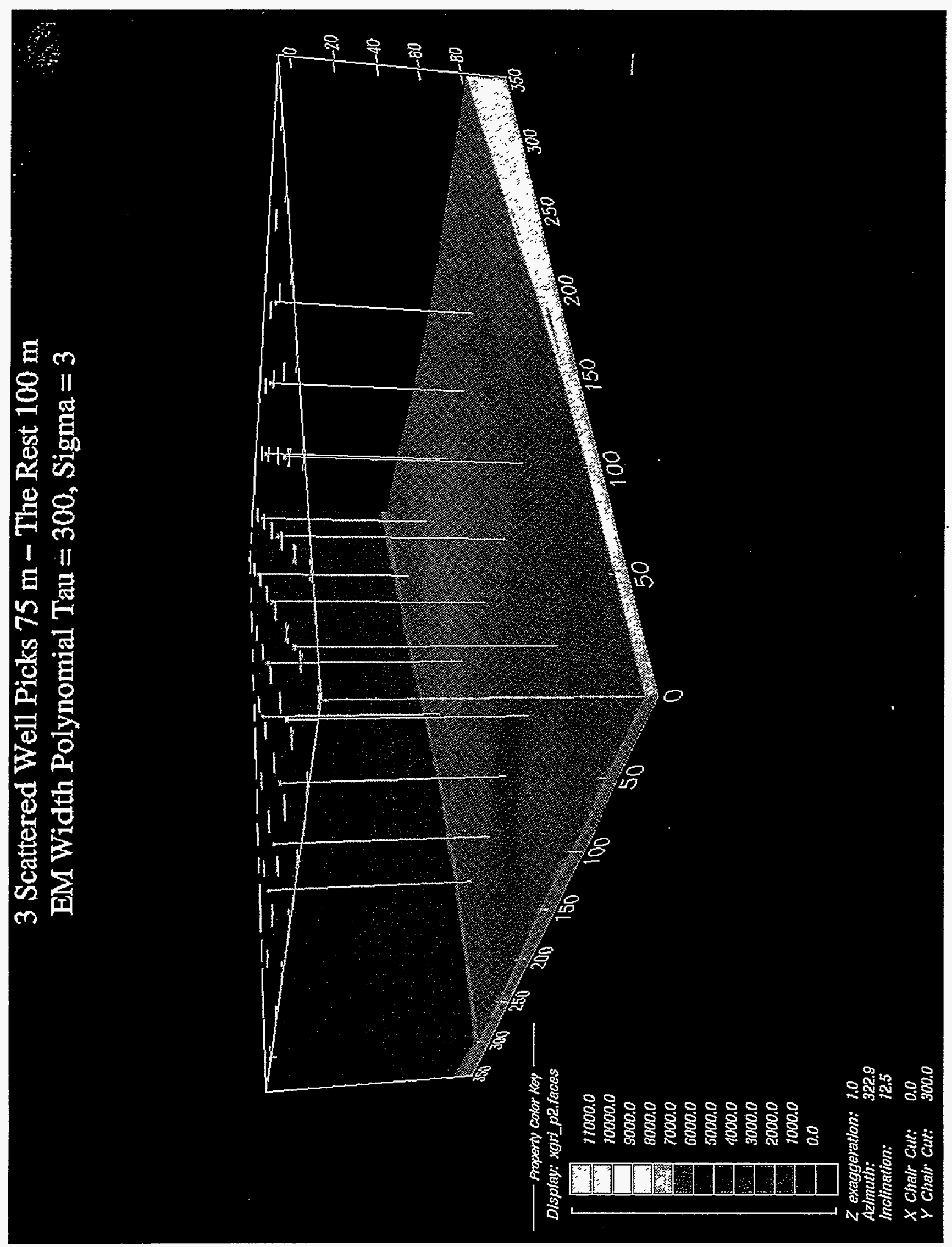


FIGURE 19. Test 4, Run 5 Results 
_... …... 


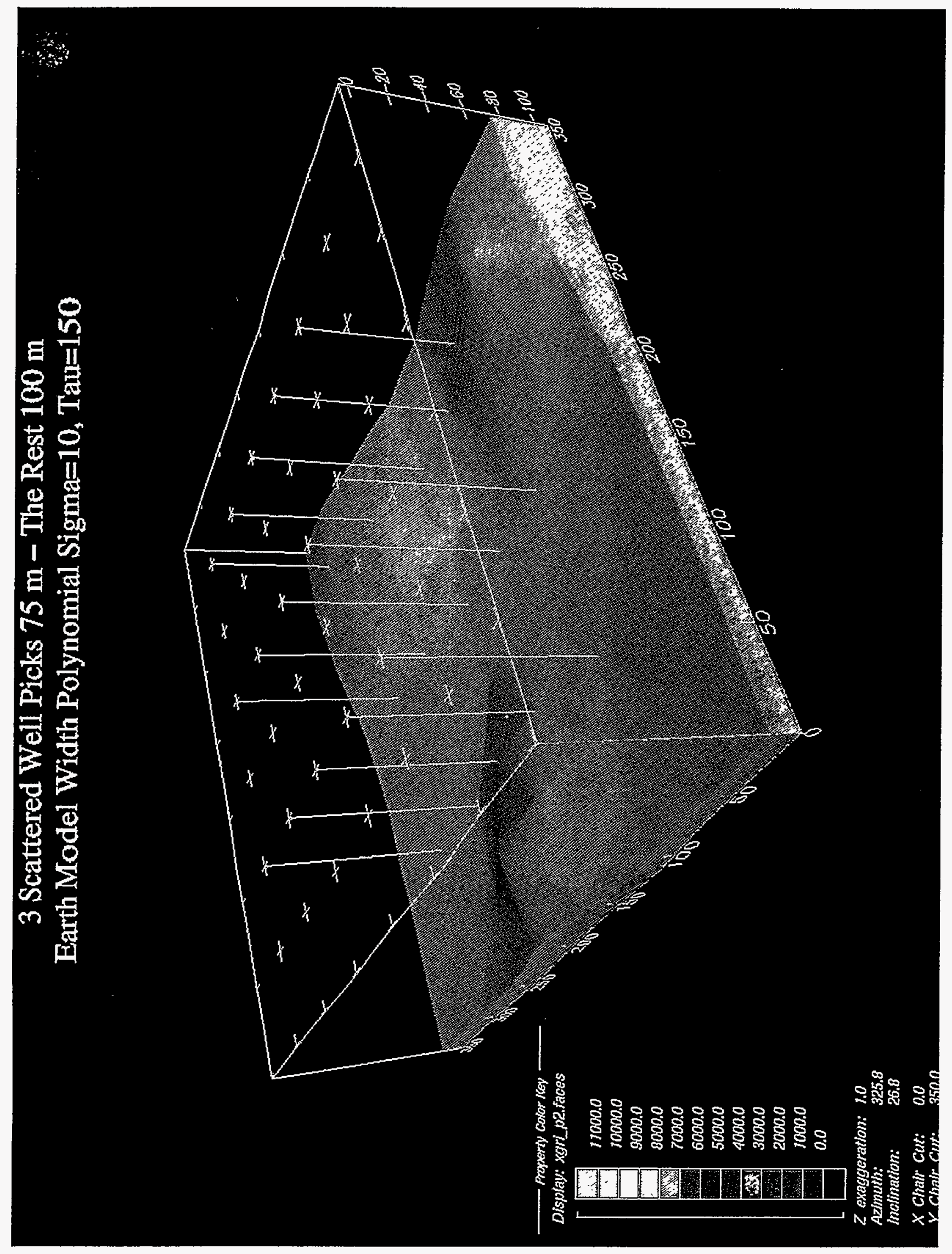


_ 
FIGURE 20. Test 4, Run 6 Results 


\section{Scattered Well Picks $75 \mathrm{~m}$ - The Rest $100 \mathrm{~m}$}

EM Width Polynomial Sigma and Tau Set to 10

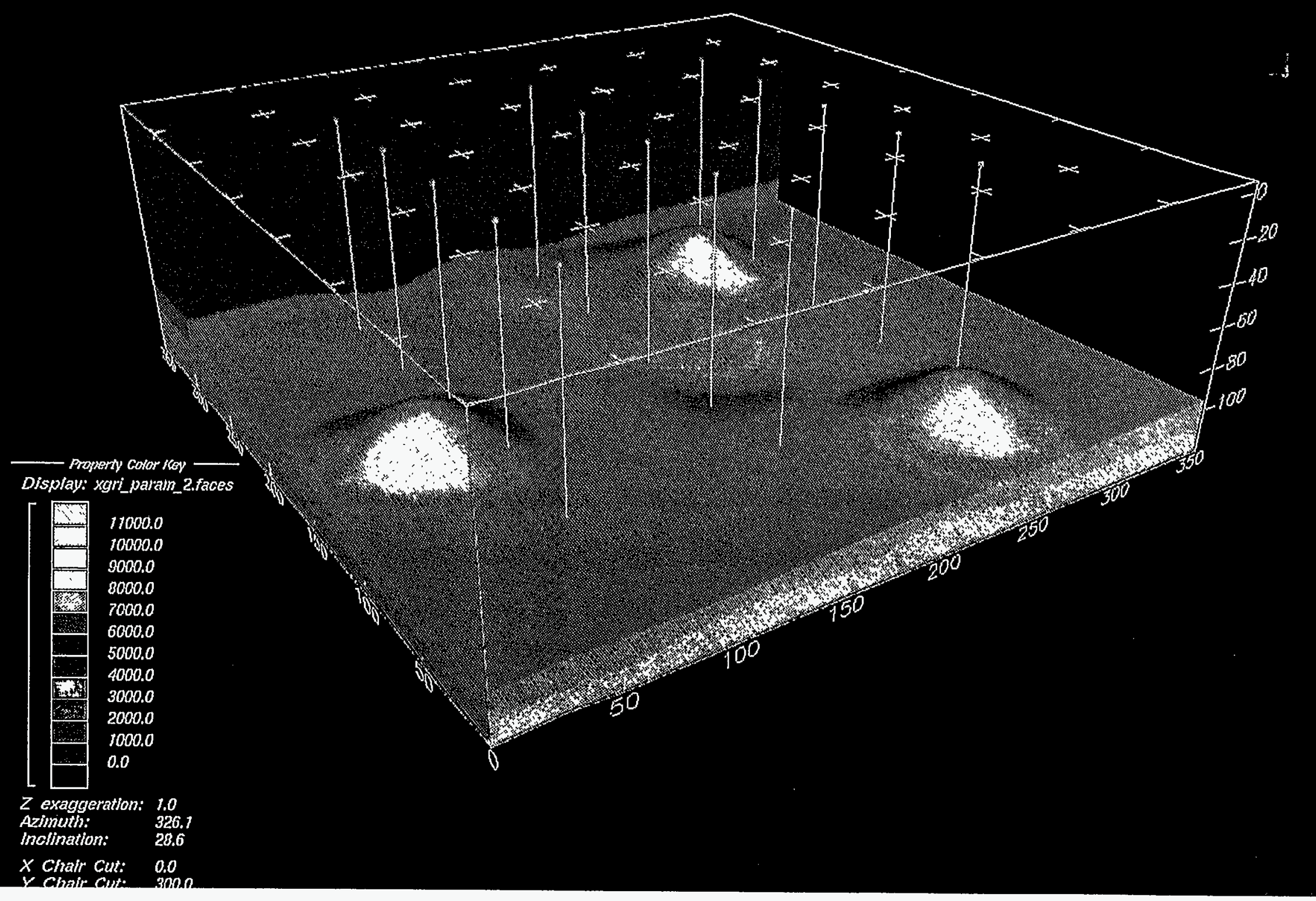


FIGURE 21. Test 4, Run 7 Results 
…- - 


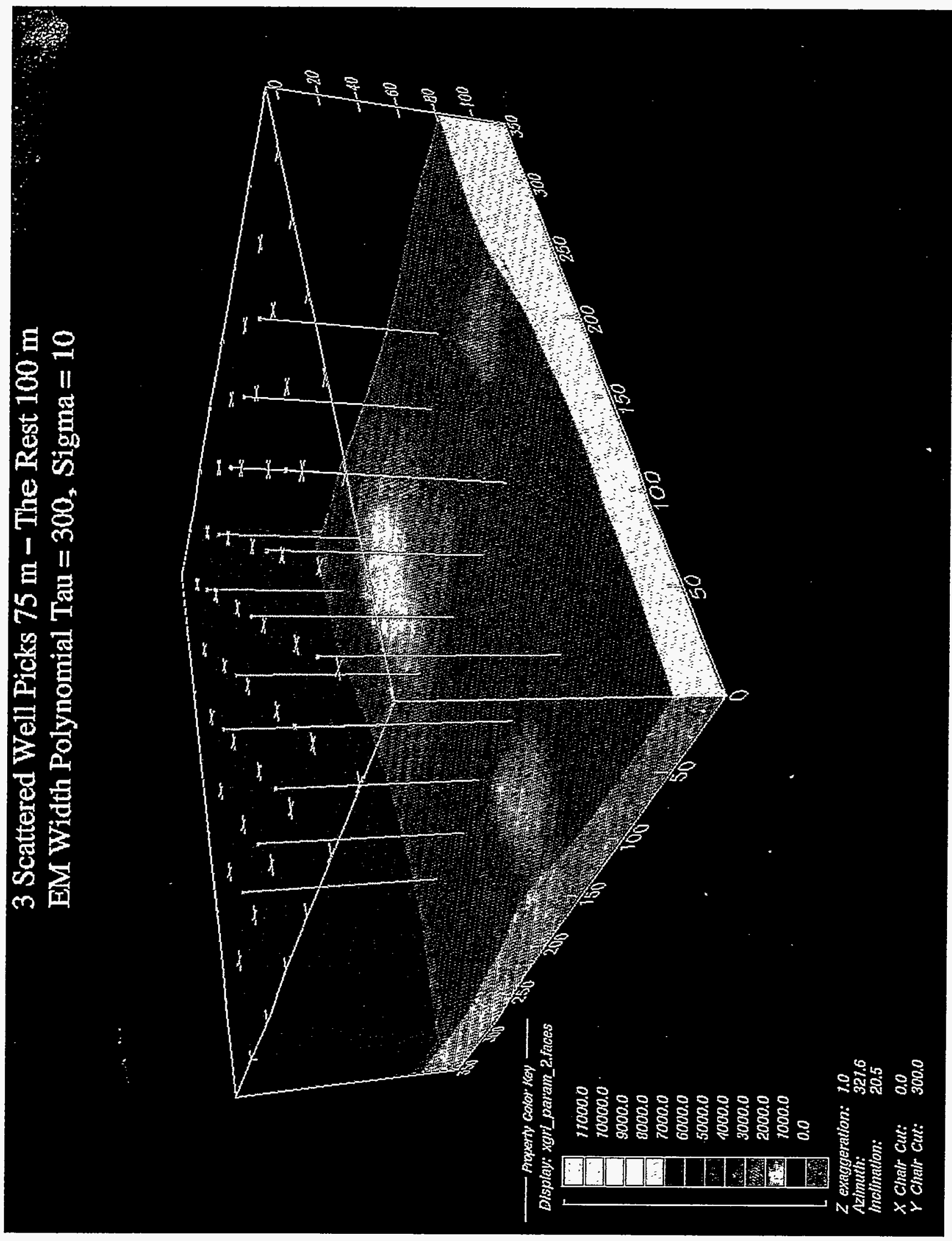


$\ldots$

- 


\section{FIGURE 22. Test 5, Run 1 Results}




\section{West Line of Well Picks $75 \mathrm{~m}$ - The Rest $100 \mathrm{~m}$ EM Width Polynomial Tau $=150$, Sigma $=3$}

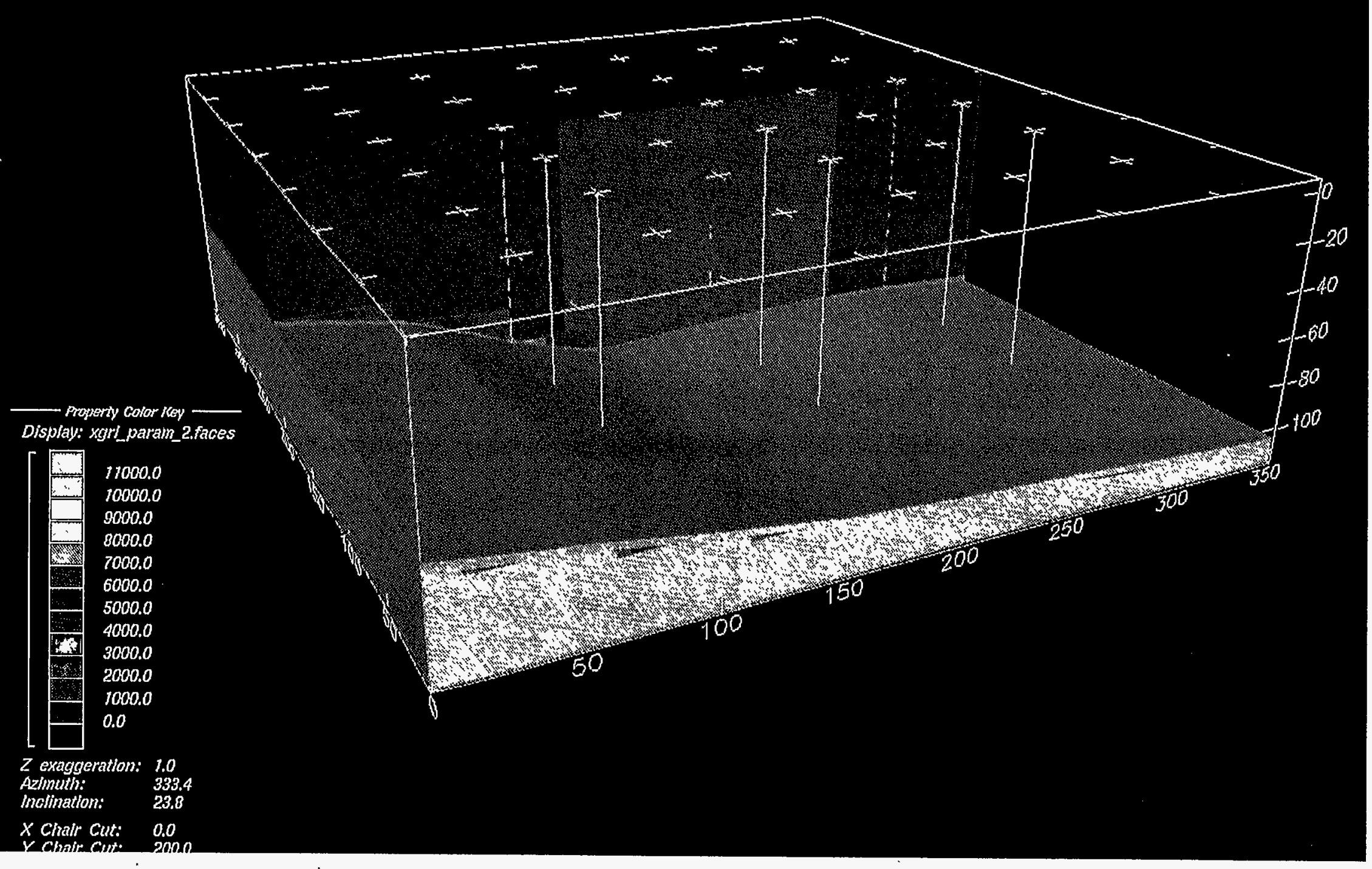


FIGURE 23. Test 5, Run 2 Results 


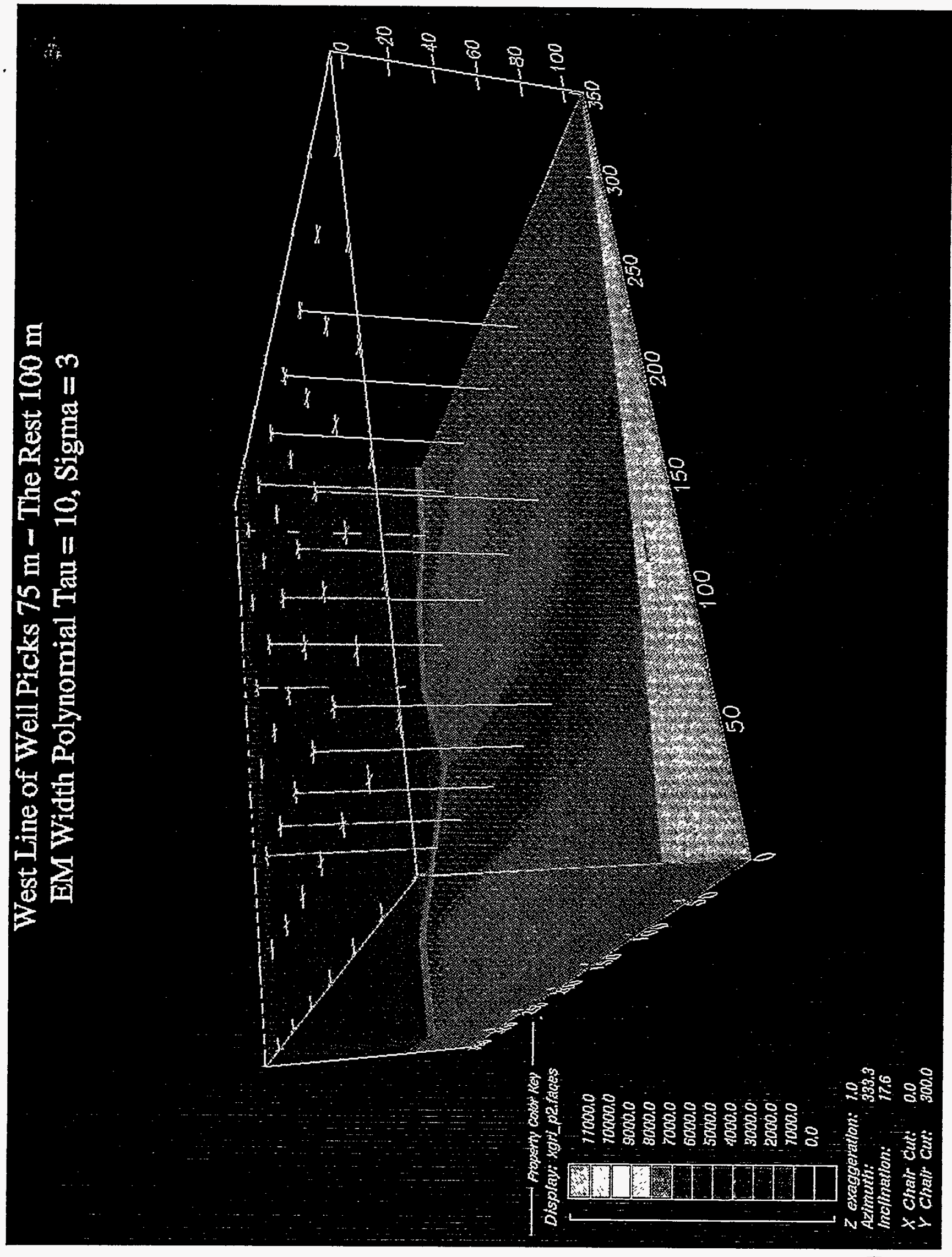




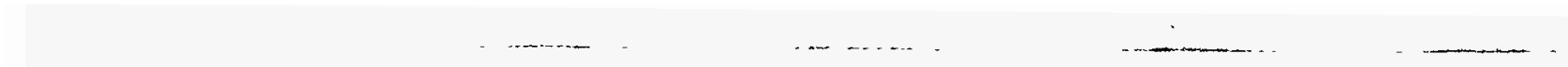




\section{FIGURE 24. Test 5, Run 3 Results}


-

.....

, 


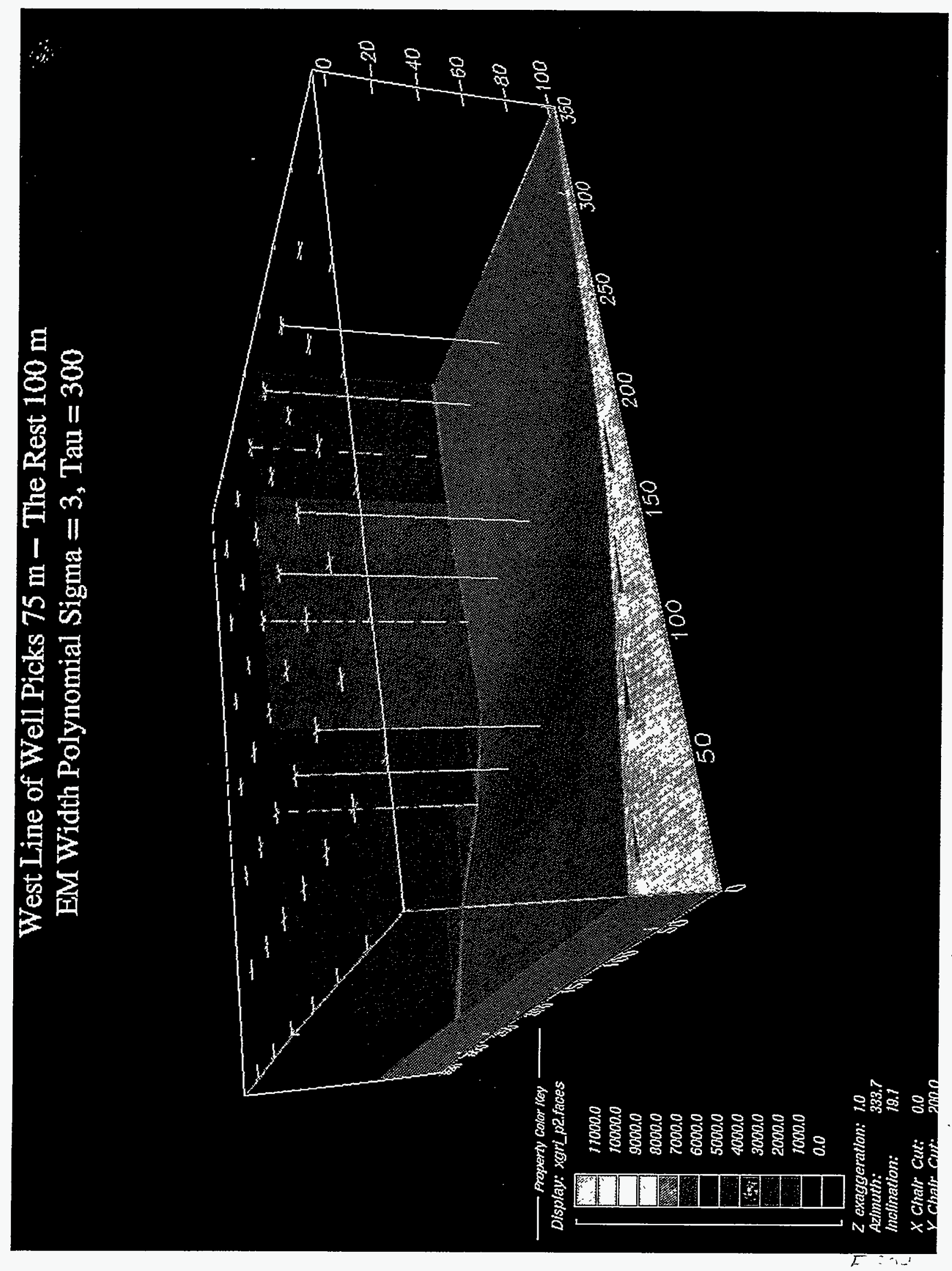


FIGURE 25. Test 5, Run 4 Results 


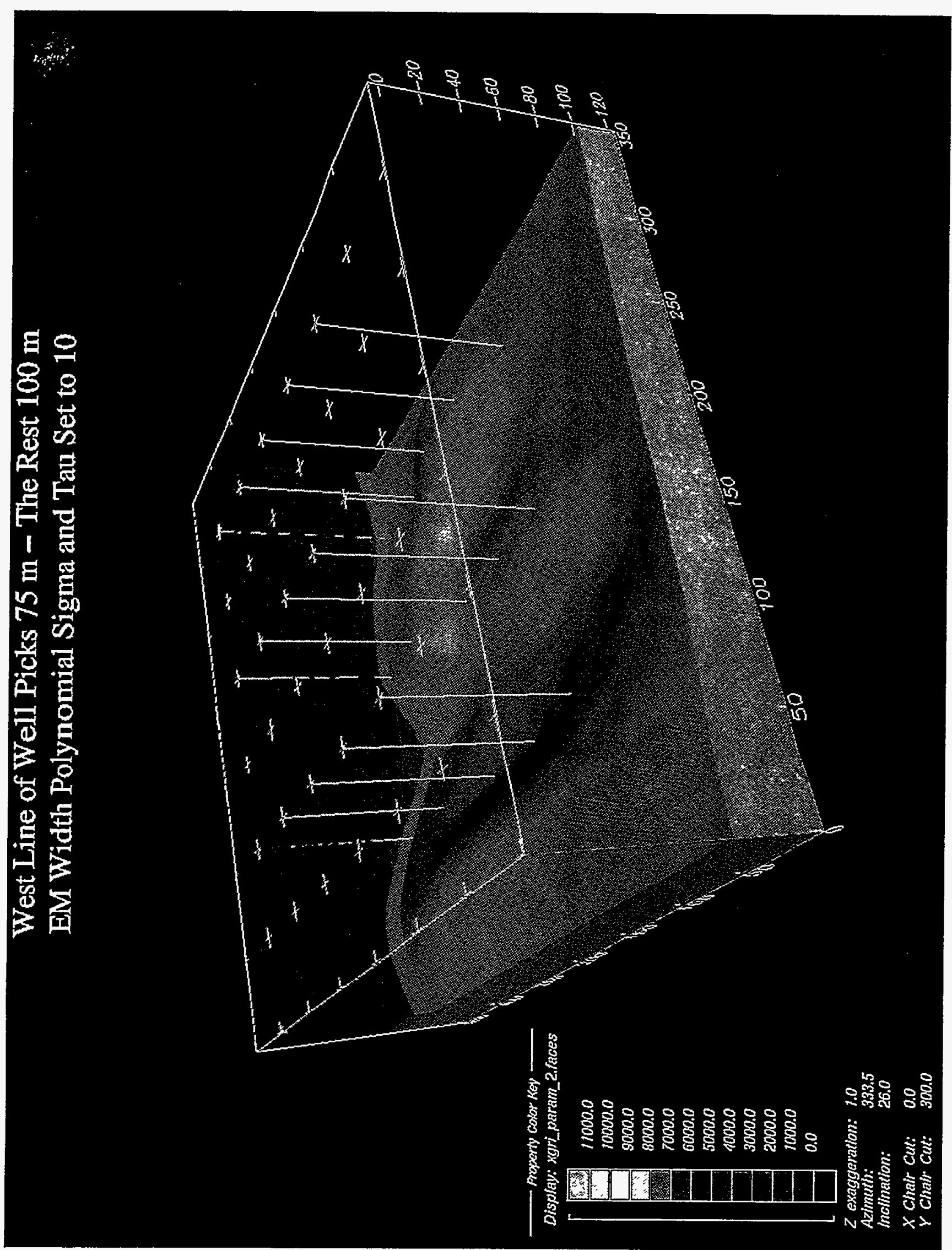


FIGURE 26. Test 5, Run 5 Results 
. . . . 


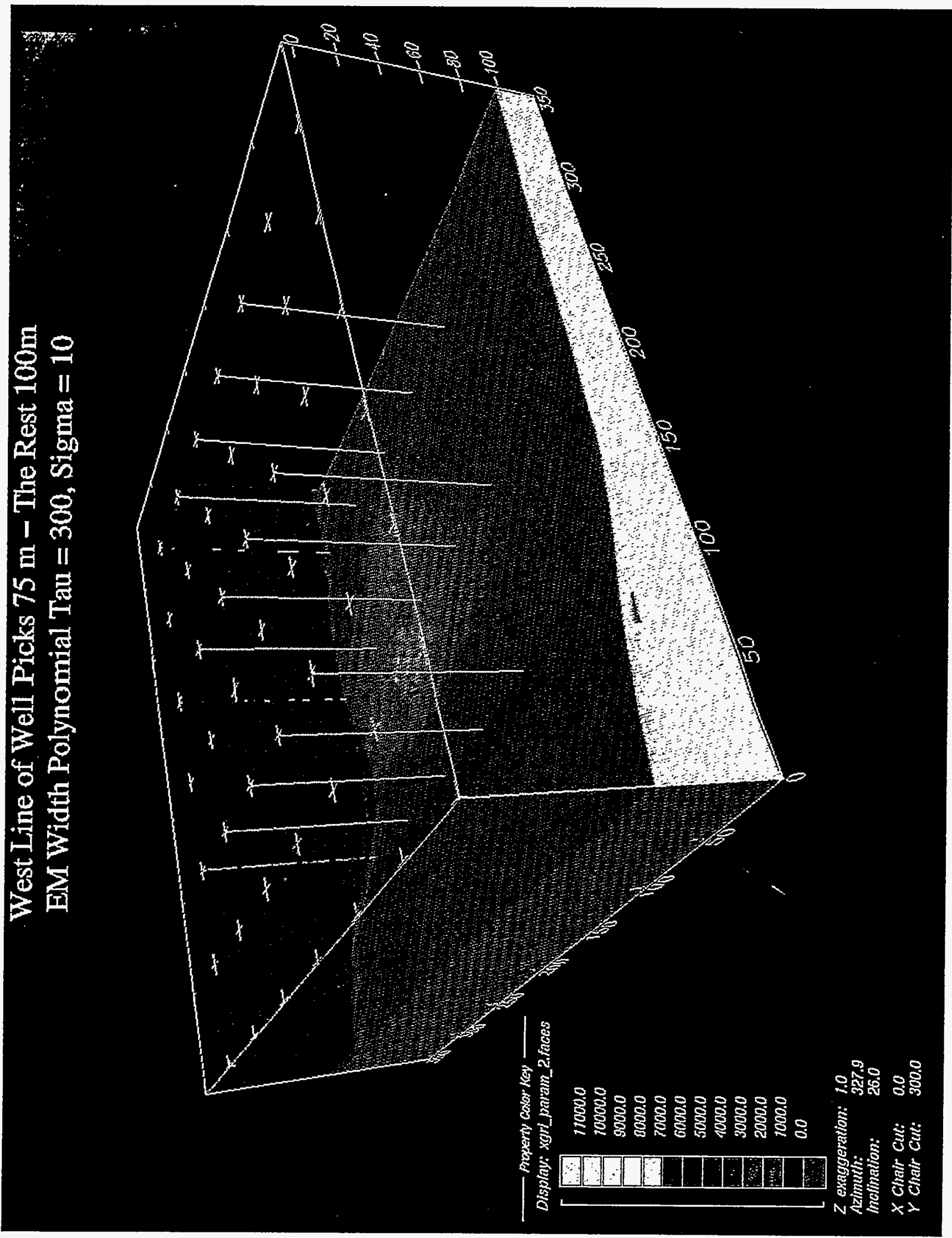


FIGURE 27. Test 6 Results 


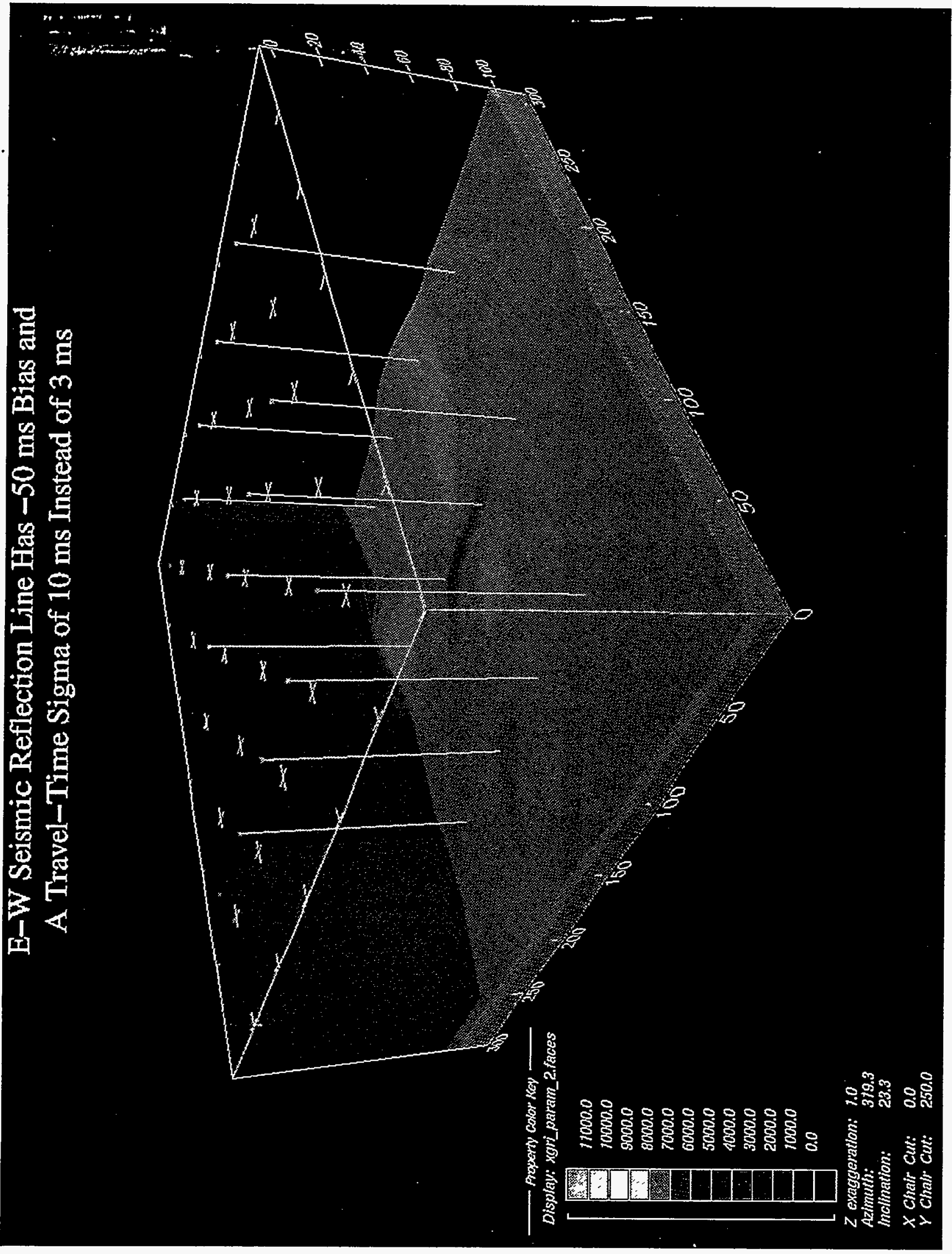


FIGURE 28a. Test 7, Run 1 Results 


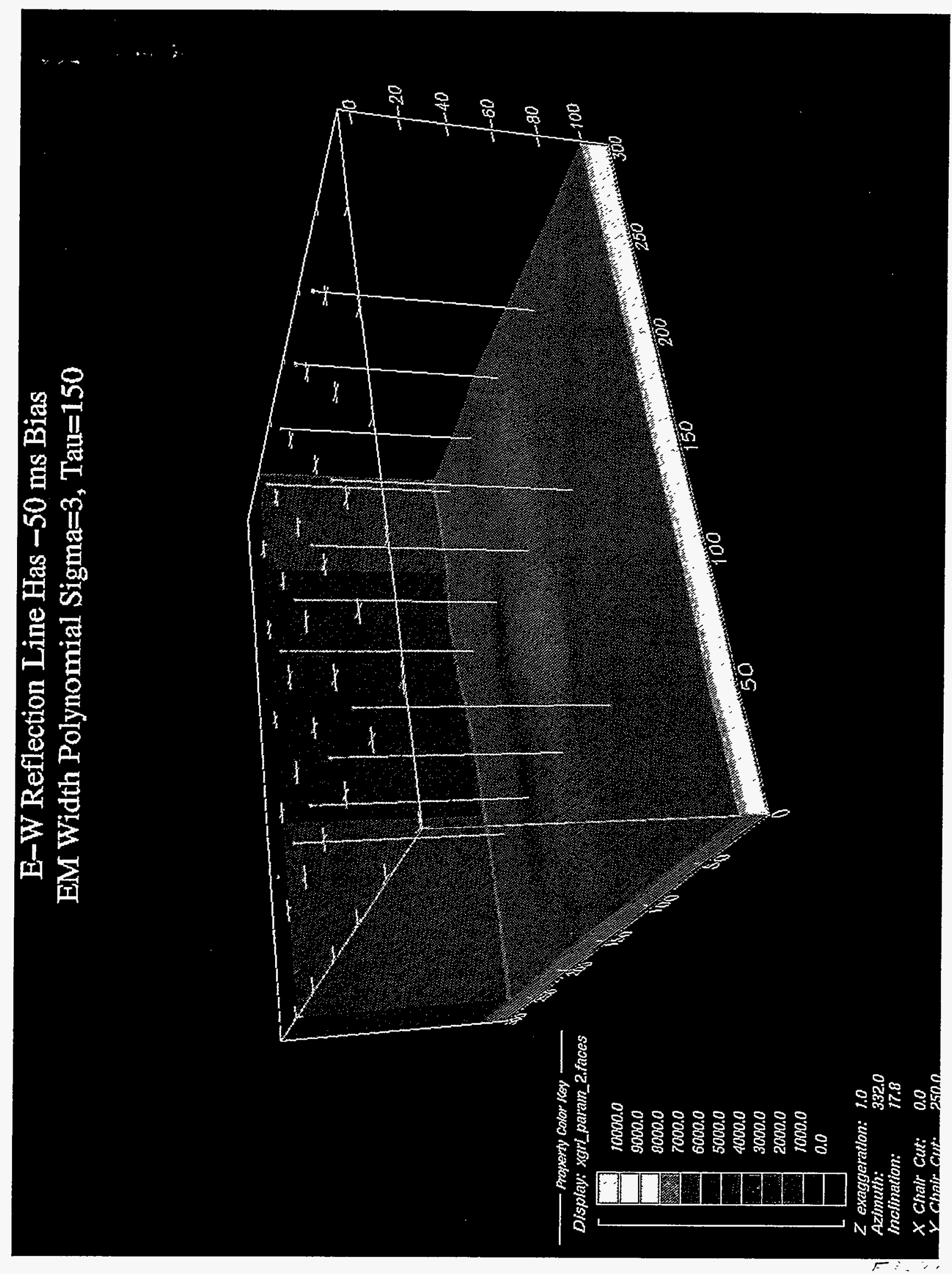


FIGURE 28b. Test 7, Run 1 Normalized Reflection Residuals Plot 


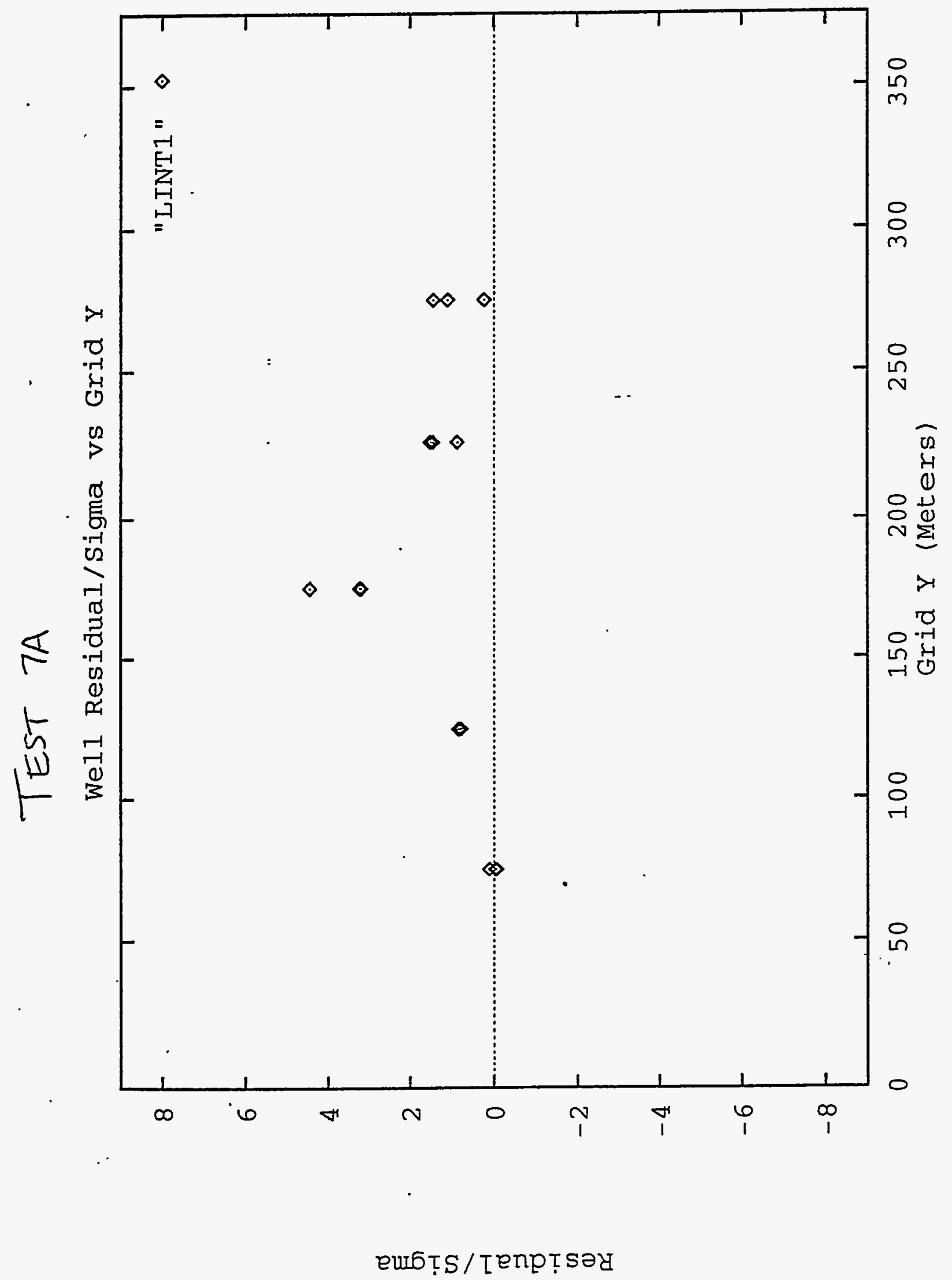




$$
\text { -... }
$$


FIGURE 28c. Test 7, Run 1 Normalized Refraction Residuals Plot 
....... 


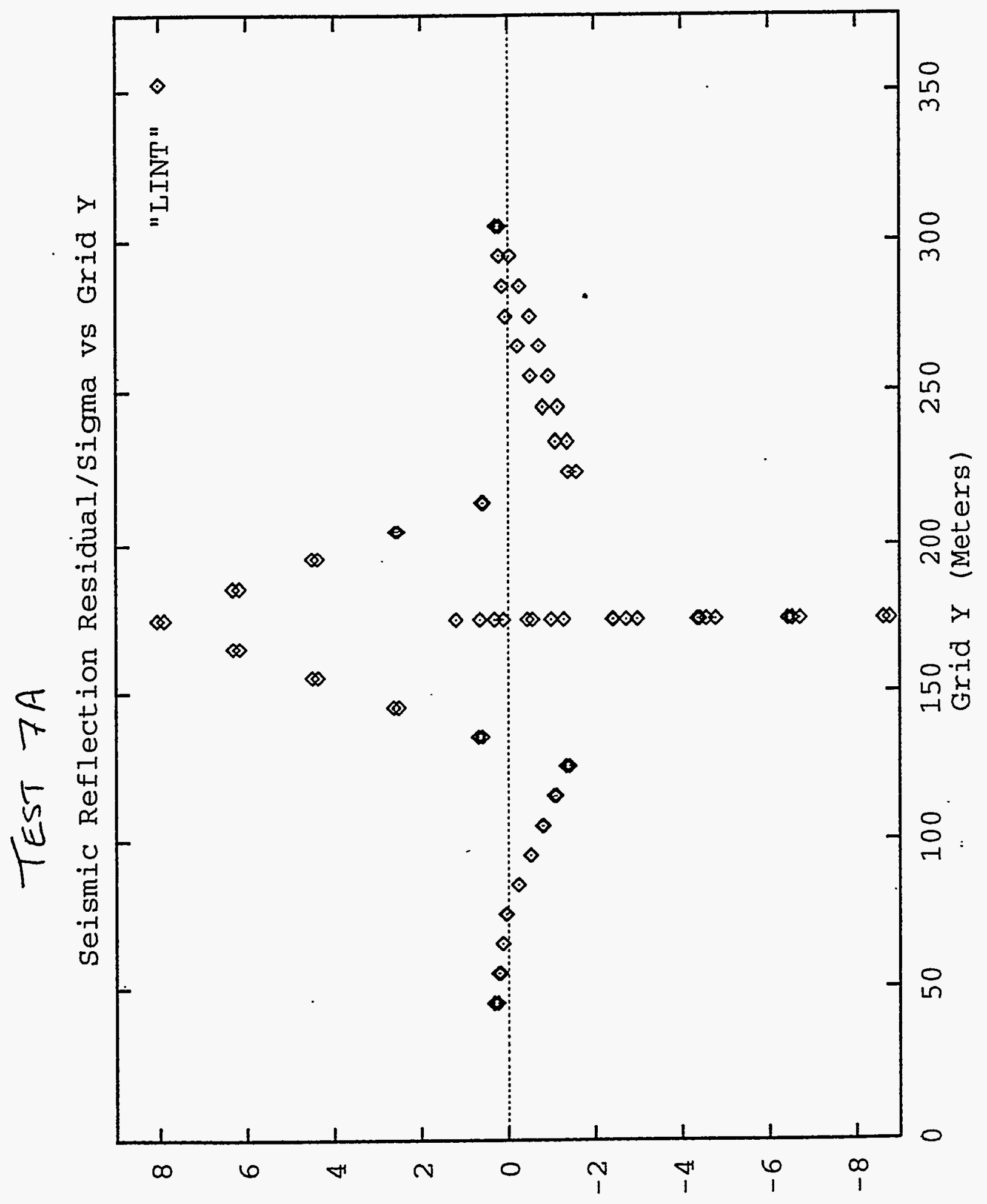

eư Ț / Tenpț səd 

. 
FIGURE 28d. Test 7, Run 1 Normalized Well Pick Residuals Plot 


$$
\text { _... - }
$$$$
\ldots
$$ 


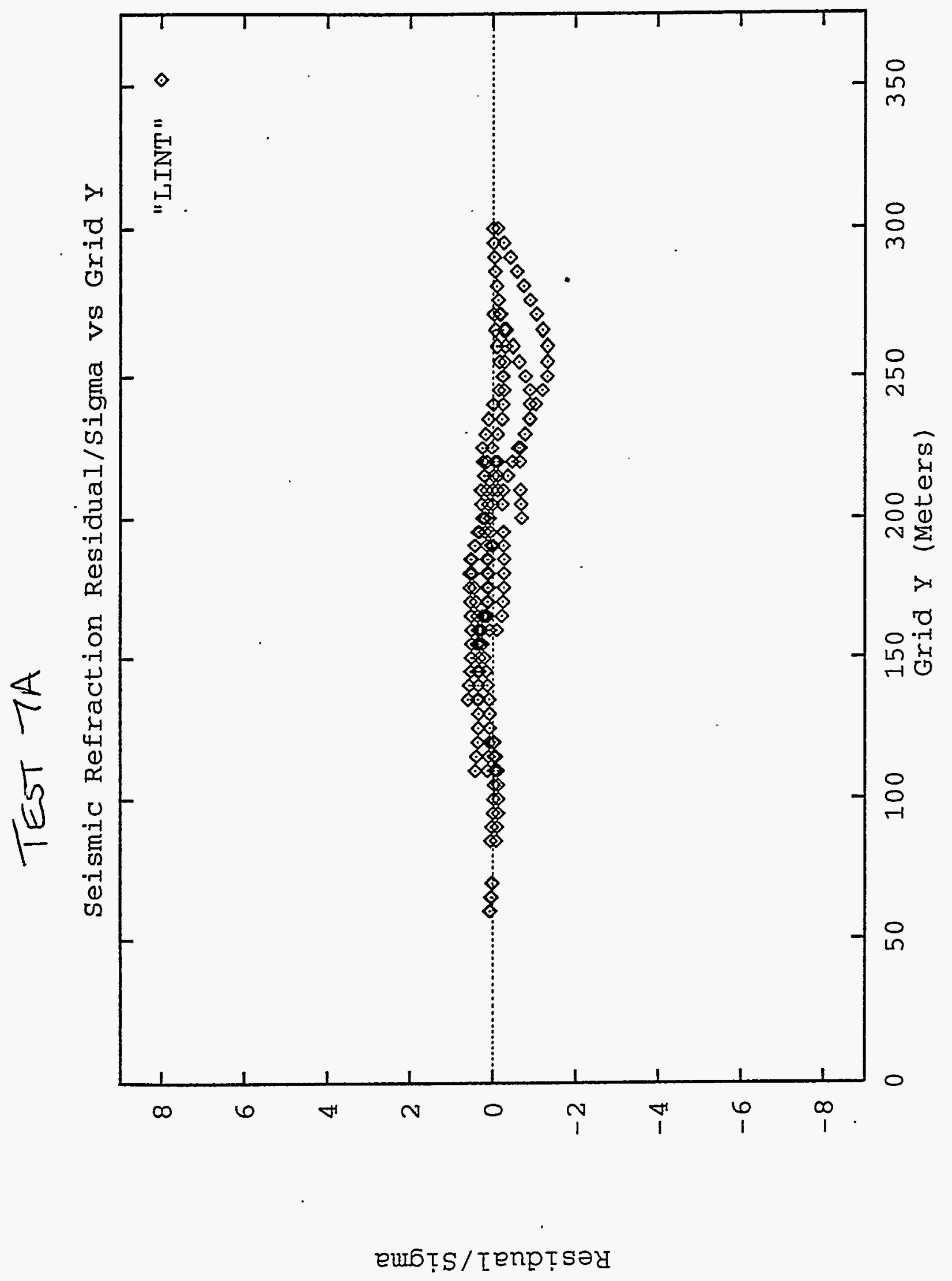


$\ldots$ 
FIGURE 29. Test 7, Run 2 Results 


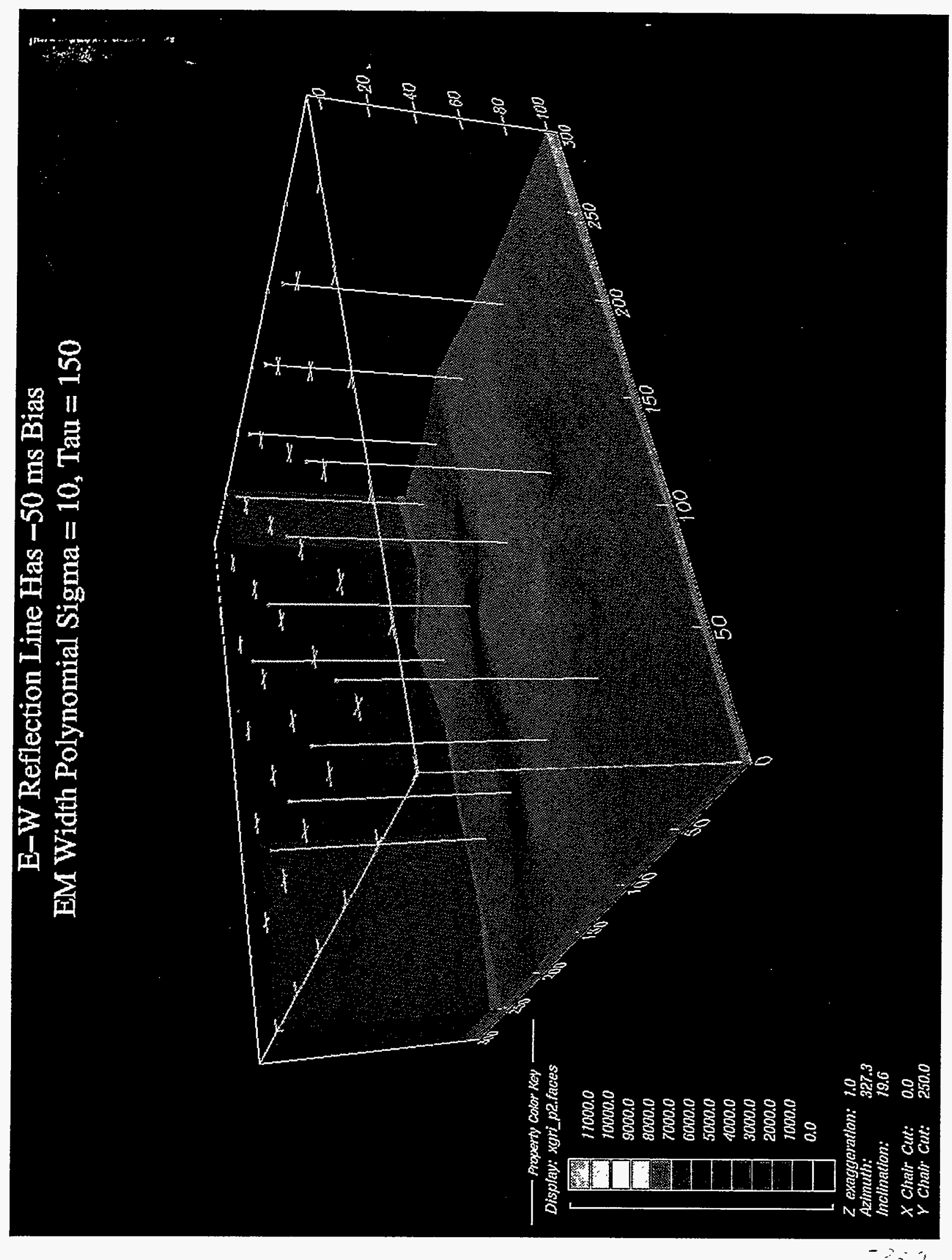


FIGURE 30. Test 7, Run 3 Results 
. 


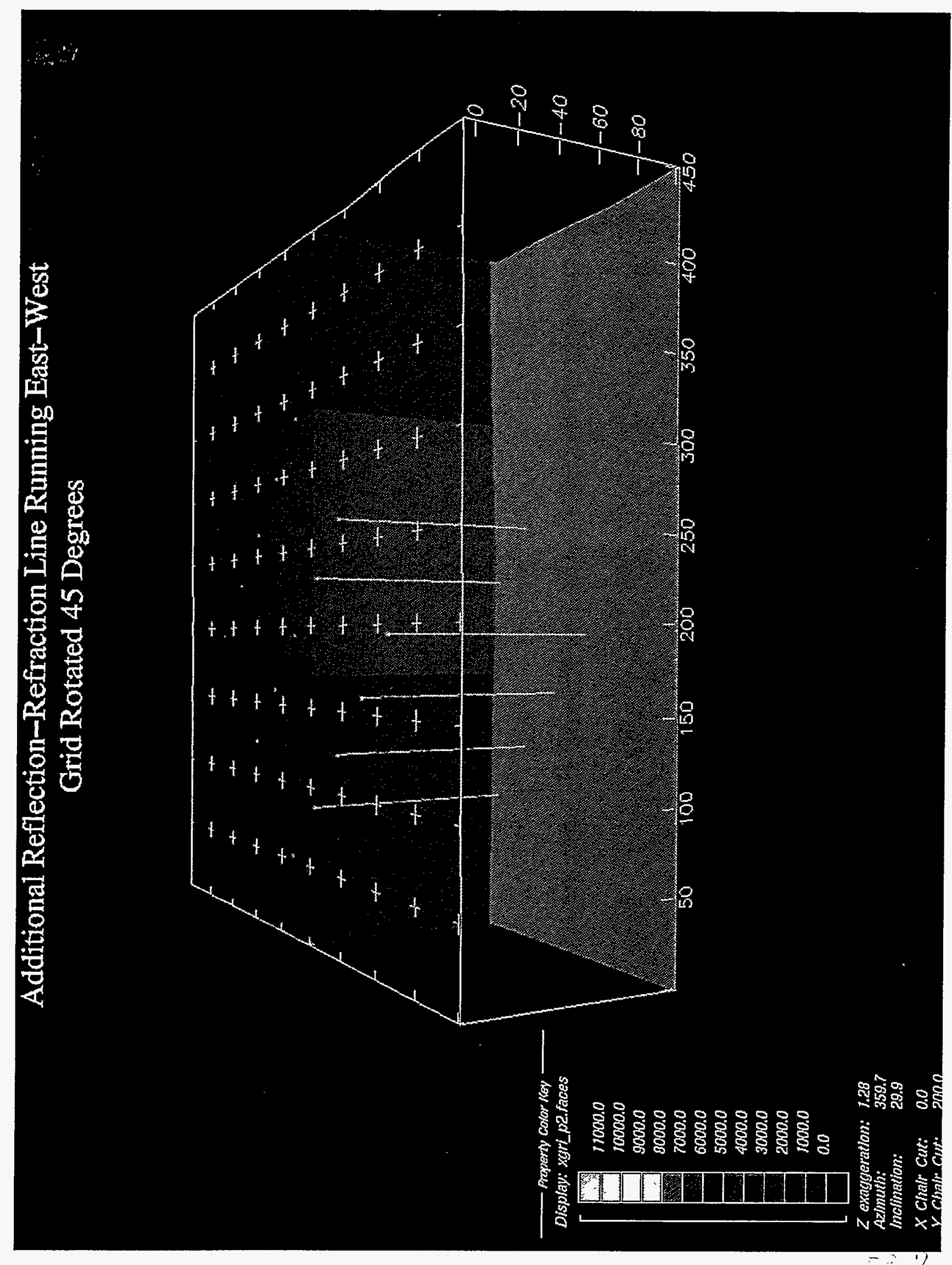




\subsection{REFERENCES}

Bierman, G.J. 1977. Factorization Methods for Discrete Sequential Estimation. Academic Press, San Diego, California.

Gibbs, B.P. 1993. Jasper Pink Fusion Workstation - Operation and Analysis (CMB/93-394). Coleman Research Corporation, Columbia, Maryland.

Hall, V.L. 1992. Mathematical Techniques in Multisensor Data Fusion. Artech House, Norwood, Massachusetts.

Porter, D.W., B.P. Gibbs, J.S. Vandergraft, W.E. Hatch, P.W. Kelsey, P. Hoekstra, B. Hoekstra, M Blohm, D. Phillips, and R. Bates. 1994. Waste Site Characterization Using Data Fusion Workstation at Hanford and Savannah River DOE Sites. Coleman Research Corporation, Columbia, Maryland. 
$\ldots \ldots$<smiles>[V][I-]</smiles> 


\section{Distribution}

No. of

Copies

\section{OFFSITE}

C.B. Purdy

DOE/Office of Technology Development

Trevion II Building

12800 Middlebrook Road

Germantown, MD 20874

Bryan J. Albers

BDM Federal, Inc.

555 Quince Orchard Road

Gaithersburg, MD 20878

Dave Porter

Coleman Research Corporation

9891 Broken Land Parkway

Suite 200

Columbia, MD 21045

Jack Stewart

10559 Rivulet Row

Columbia, MD 21044
No. of

Copies

ONSITE

DOE Richland Operations Office

D.E. Trader

K8-50

Westinghouse Hanford Company

S.M. Narbutovskih

K6-06

Bechtel Hanford Inc.

M.P. Connelly

$\mathrm{X} 0-37$

21 Pacific Northwest Laboratory

G.R. Holdren

K6-81

G.V. Last

K9-48

R.E. Lewis (5)

K9-48

P.E. Long

K9-48

D.L. Whitworth (6)

K9-08

Information Release Office (7) K1-06

Distr.1 